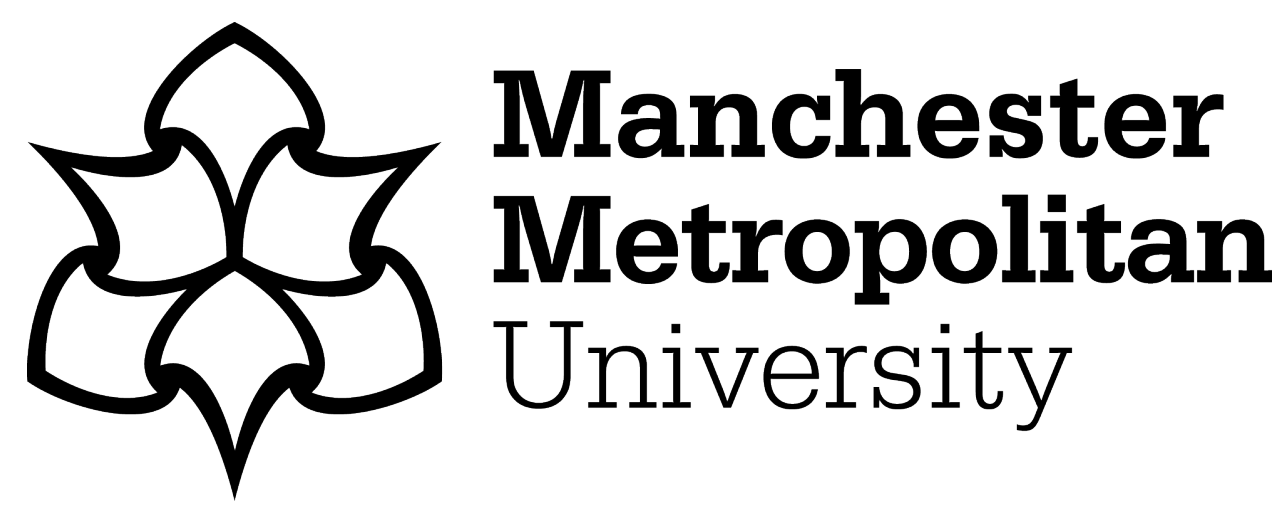

Ge, P, Hou, H, Banks, CE, Foster, CW, Li, S, Zhang, Y, He, J, Zhang, C and Ji, $X$ (2018) Binding MoSe2 with carbon constrained in carbonous nanosphere towards high-capacity and ultrafast Li/Na-ion storage. Energy Storage Materials, 12. pp. 310-323. ISSN 2405-8297

Downloaded from: https://e-space.mmu.ac.uk/620836/

Publisher: Elsevier

DOI: https://doi.org/10.1016/j.ensm.2018.02.012

Usage rights: Creative Commons: Attribution-Noncommercial-No Derivative Works 4.0

Please cite the published version 


\title{
Binding $\mathrm{MoSe}_{2}$ with carbon constrained in carbonous nanosphere towards High-Capacity and Ultrafast Li/Na-Ion Storage
}

\begin{abstract}
:
Mostly reported $\mathrm{MoSe}_{2}$ suffered from easily stacking problem, volume expansion and relative low capacity. From the experience of $\mathrm{Li} / \mathrm{Na}-\mathrm{Se}$ batteries, the exfoliated and encapsulated $\mathrm{MoSe}_{2}$ inside carbon nanospheres with $\mathrm{C}-\mathrm{O}-\mathrm{Mo}$ bonds and large layer distance $(0.89 \mathrm{~nm})$ are successfully constructed. This unique effective structure has C-O-Mo bonding allowing high conductivity across the Se-O insulation layer and promoting its reversible conversion. The first-principles calculations demonstrated that the frontier molecular orbitals of C-O-Mo interface structure are mainly localized on the $\mathrm{MoSe}_{2}$ sheet fragment with an appropriate HOMO-LUMO gap $(<4 \mathrm{eV})$, suggesting its good stability and conductivity. Utilized as anodes for LIBs allows a Li-storage capacity to be realized of $1208 \mathrm{mAh} \mathrm{g}^{-1}$ after 150 cycles at $1.0 \mathrm{~A} \mathrm{~g}^{-1}$ and $519 \mathrm{mAh} \mathrm{g}^{-1}$ after 200 cycles at $4.0 \mathrm{~A} \mathrm{~g}^{-1}$. The Na-storage capacity is found to be 543 , $491 \mathrm{mAh} \mathrm{g}^{-1}$ after 120 cycles at $0.1,1.0 \mathrm{~A} \mathrm{~g}^{-1}$. Focusing on the analysis of $\mathrm{CV}$, the reducing particle may improve the capacitive behaviors, further resulting the high-rate performance. Ex-situ techniques demonstrated that the emerging Se was constrained uniformly. The controlling of by-product Se plays a key role in achieving a high rate
\end{abstract}


capacity and cycling stability, and opens up a potential avenue for these metal-selenide anodes designs for battery storage systems.

Keywords: $\mathrm{MoSe}_{2}$, in-situ generated Se, lithium ions battery, sodium ions battery, electrochemistry

\section{Introduction}

Recently, owing to the promising lithium/sodium-selenium batteries, metal-selenium have captured widespread interests.[1] Despite the cost of Se, its stable electrochemical reaction and less solubility are more valuable in practical application. $\mathrm{MoSe}_{2}$, as a rising star in TMDCs family, possesses numerous primary advantages, containing narrowe band-gap $(1.1 \mathrm{eV})$, large interlayer distances $(0.65 \mathrm{~nm})$ and high electronic conductivity (Se brings the metallic nature, $1 \times 10^{-3} \mathrm{~S} \mathrm{~m}^{-1}$ ), which could lower the energy-consumption of electron transition, increase the shuttling rate of alkali metal ions and thus reduce the electron transport resistance.[2] Based on the sole conversion reaction $\left(\mathrm{MoSe}_{2}+4 \mathrm{Li}^{+} / \mathrm{Na}^{+}+4 \mathrm{e}^{-} \rightarrow \mathrm{LiSe}_{2} / \mathrm{NaSe}_{2}+\mathrm{Mo}\right)$, the theoretically capacity of $\mathrm{MoSe}_{2}$ reaches to $422 \mathrm{mAh} \mathrm{g}^{-1}$, but the exceeding $\mathrm{Li} / \mathrm{Na}$-storage capacity has been reported in the previous works by Tang et al. and Wang et al, $[3,4]$ demonstrating the potential of capacity as a promising anode within LIBs/SIBs. Nevertheless, for the metal-selenide materials, the large volume variation, inferior mechanical stress and relative low Na-storage capacity, were all major challenges.[1,2] Two approaches were employed to address these issues, including 
the engineering of morphology and introduction of carbon materials. Generally speaking, the reducing particles size is in favor of improving the contracting areas with the electrolyte, which could shorten the pathways of $\mathrm{Li} / \mathrm{Na}$ diffusion, thereby giving rise to the increased rate capability.[5] Different morphologies of $\mathrm{MoSe}_{2}$ with diverse sizes have been designed and their electrochemical properties were explored, such as the microsphere, yolk-shell structure, nanosheets and other special morphologies.[2] The $\mathrm{MoSe}_{2}$ nanospheres have been obtained through a simple colloidal route, exhibiting a high initial discharge/charge capacity of 520/430 $\mathrm{mAh} \mathrm{g}^{-1}$ when utilized as anodes within SIBs.[6] On the other hand, coupling $\mathrm{MoSe}_{2}$ with carbon is deemed as the effective way to reduce the accumulated strain, control the volume expansion as well as ensure the fast alkali ions.[7] After the activated treatment of carbon nanotube/graphene, $\mathrm{MoSe}_{2}$ could successfully grow upon the surface of substrate, accelerating the swelling of electrolyte and the shuttling of alkali ions.[8] Incorporating 1T-MoSe 2 with SWCNT into the conductive structure was prepared by Song's group,[9] delivering a capacity of $630 \mathrm{mAh} \mathrm{g}^{-1}$ at $3.0 \mathrm{~A} \mathrm{~g}^{-1}$. However, similar to the deficient defects of $\mathrm{MoS}_{2}$, that of $\mathrm{MoSe}_{2}$ should be emphasized: (1) the Mo nanoparticles replaced by alkalis ions would largely agglomerate and move outward easily; (2) the dissolution of the in-situ generated selenide due to the weaker bonding force of Mo-Se than that of Mo-O/S could result in the rapid capacity fading.[10] The growth of $\mathrm{MoSe}_{2}$ upon the conductivity substrate could lead to a large specific surface area of $\mathrm{MoSe}_{2} /$ graphene or nanotube exposed in 
the electrolyte, accompanying with the deteriorated adverse reaction, whilst the Mo-containing ions and in-situ generated Se cannot be timely captured for the reverse process. All of the aforementioned drawbacks would bring the poor electrochemical properties of $\mathrm{MoSe}_{2}$.

The rational design of $\mathrm{MoSe}_{2} / \mathrm{C}$ is crucial for improving the $\mathrm{Li} / \mathrm{Na}$-storage abilities, including the enlarged interlayer spacing and the coated carbon layer-by-layer. For this purpose, the selected carbon sources could act as two roles: the exfoliated and covered agents. Taking into consideration of the liquid-phase reaction environment, non-ionic surfactant / polymer-assisted exfoliation methods should be emphasized owing to their additional stabilization and dispersing features.[11] Polyvinyl pyrrolidone (PVP), as one of nine non-ionic surfactants (e.g. Pluronic P-123, n-dodecyl b-dmaltoside), can be easily attached to the surface of $\mathrm{MoSe}_{2}$ through strong adsorption forces, allowing this coated $\mathrm{MoSe}_{2}$ to form hybrid nanosheets, originated from the well solubility and wetting properties.[12-15] Recent work displays the successful formation of PVP-coated $\mathrm{MoSe}_{2}$ nanosheets utilized as biocompatible photothermal therapy agents.[13]

In this work, the nanospheres (diameter of $100 \mathrm{~nm}$ ) composed of PVP-coated $\mathrm{MoSe}_{2}$ nanosheets were prepared expectedly, after a carbonization process, allowing for the large interlayer distance, C-O-Mo bonds and layer-by-layer nitrogen-doped carbon heterostructure. Inspiringly, the obtained $\mathrm{MoSe}_{2} / \mathrm{N}-\mathrm{C}$ anode for LIBs delivers larger capacities of 769.7 and $273.2 \mathrm{mAh} \mathrm{g}^{-1}$ at 2.0 and $8.0 \mathrm{~A} \mathrm{~g}^{-1}$, respectively. 
Surprisingly, as anodes for SIBs, the prepared sample has an excellent reversible capacity of $552.1 \mathrm{mAh} \mathrm{g}^{-1}$ at $0.1 \mathrm{~A} \mathrm{~g}^{-1}$ after 120 cycles. Even at 2.0 and $8.0 \mathrm{~A} \mathrm{~g}^{-1}$, it still remains at 441.7 and $236.4 \mathrm{mAh} \mathrm{g}^{-1}$ respectively. The high-capacity and ultrafast Li/Na-ion storage are mainly due to: (1) the open nanostructure enlarged connecting area with the electrolyte; (2) the expanded interlayer of $\mathrm{MoSe}_{2}$ decreased the electron-shuttling resistance and increased the accessible active sites; (3) the in-situ generated selenium was effectively confined in the carbon substrate, which improves the Li/Na-storage capacity distinctly. In addition, the experimental and computational results consistently indicated the formation of the unique C-O-Mo bonds in the novel $\mathrm{MoSe}_{2} / \mathrm{C}$ battery material, which would be beneficial to stabilizing the volume expansion and give a faster rate of electron transfer. Furthermore, the first-principles calculations predicted that the unique C-O-Mo bond should make the hybrid materials possess a superior general performance (good stability and excellent conductivity).

\section{Experimental section}

2.1 Synthesis of $\mathrm{MoSe}_{2}$ hollow flower spheres (FMS) and $\mathrm{MoSe}_{2} / \mathrm{N}-\mathrm{C}$ (PMS) nanospheres

$0.156 \mathrm{~g}$ Se and $0.156 \mathrm{~g} \mathrm{MoO}_{3}$ was added to $25 \mathrm{~mL}$ hydrazine hydrate, followed by 30 min magnetic stirring at $300 \mathrm{rpm}$ to form solution A. $2.0 \mathrm{~g} \mathrm{NH}_{4} \mathrm{~F}$ and $0.8 \mathrm{~g}$ PVP were dissolved in $50 \mathrm{~mL}$ deionized water (DI water), then $75 \mathrm{~mL}$ ethanol was injected, with 30 min stirring to obtain solution B. Solution A was added drop-wise to solution B, the mixed solutions were stirred for $30 \mathrm{~min}$ at $600 \mathrm{rpm}$ and further ultrasonicated for 
1h. The final well-distributed solution was transferred to an autoclave and remained at $180{ }^{\circ} \mathrm{C}$ for $12 \mathrm{~h}$. The autoclave was naturally cooled down to room temperature. The liquid suspension was centrifuged at $11000 \mathrm{rpm}$ for 5 min and washed thoroughly with water and ethanol three times. The black products were dried at $80{ }^{\circ} \mathrm{C}$ and further calcined at $500{ }^{\circ} \mathrm{C}$ in the Ar atmosphere to obtained PMS nanospheres. Without the introduction of PVP, $\mathrm{MoSe}_{2}$ hollow flower spheres through the same procedures were prepared, named FMS. The commercial $\mathrm{MoSe}_{2}$ (Alpha) via the sintering process was named CMS.

\subsection{Electrochemical Characterization:}

The structure features were investigated through Power X-ray diffractometer (Rigaku D/max 2550 VB+18 kW, Japan), Laser Micro-Raman Spectrometer (Renishaw InVia, UK) and thermogravimetric analysis (TGA, NETZSCH STA449F3). X-ray photoelectron spectroscopy (XPS, K-Alpha 1063, UK) is used to analyze those chemical valences. The micro-morphologies were investigated through scanning electron microscopy (SEM, a JEM-2100F instrument at $200 \mathrm{kV}$ ) and Transmission electron (TEM, JEM-2100F).

\subsection{Electrochemical Measurements.}

The homogeneous slurry was obtained via mixing active materials, Super P (acetylene black), and hydroxymethyl cellulose (CMC) with a weight ratio of $80: 10: 10$ in deionized water (DI water). After the doctor blading of the slurry on the $\mathrm{Cu}$ foil, it was dried in a vacuum oven at $60{ }^{\circ} \mathrm{C}$ for $10 \mathrm{~h}$. The metal $(\mathrm{Li} / \mathrm{Na})$ and the as-prepared 
electrodes were assembled in the argon glovebox. The separator was Celgard2400 and the electrolyte was $1 \mathrm{M} \mathrm{NaClO}_{4}$ in propylene carbonate (PC) with $5 \%$ fluoroethylene carbonate (FEC) additive. The galvanostatic discharge/charge tests were performance on a Land CT 2001 battery and Arbin battery cycler (BT2000) between 0.01 and 3.0V. Utilizing the AUTOLABEL MULTI AUTOLAB M204 instruments under various conditions, the electrochemical impedimetric (EIS) and cyclic voltammetric (CV) measurements were explored.

\subsection{First-principles Calculations}

\subsubsection{Simplified computational models}

To balance the calculation accuracy and computational cost, the simplified computational cluster models of $\mathrm{MoSe}_{2}$ sheet fragment and graphene fragment (C60 fullerene) are proposed to represent the $\mathrm{MoSe}_{2}$ and carbon materials, respectively. The $\mathrm{MoSe}_{2}$ sheet fragment is directly generated from the experimental crystal structure of $\mathrm{MoSe}_{2}$, which contains five Mo atoms, and each Mo atom is coordinated by two Se atoms. Oxidized graphene fragment is prepared by running a full optimization calculation for a system in which an oxygen atom is placed onto the center of a simplified graphene fragment (pyrene). Similarly, oxidized C60 fullerene is obtained by optimizing a system in which an oxygen atom is placed on to a carbon atom of C60 crystal structure. Then, these well-prepared fragments (as displayed in Figure 3) were assembled to construct C-O-Mo interface models, which are further optimized to obtain C-O-Mo interface structures ( as shown in Figure 3). 


\subsubsection{Computational details}

All the first-principles calculations are performed by using the version D01 of Gaussian 09. Specifically, the state-of-the-art hybrid functional B3LYP and $\omega$ B97XD are adopted with basis set of 6-31G* on $\mathrm{C}, \mathrm{O}$ atoms, and LanL2DZ with efficient core potential (ECP) on Mo and Se atoms. The LAN2DZ ECP for Mo replaces the innermost 28 electrons $\left[1 \mathrm{~s}^{2} 2 \mathrm{~s}^{2} \mathrm{p}^{6} 3 \mathrm{~s}^{2} \mathrm{p}^{6} \mathrm{~d}^{10}\right]$ in Mo by a relativistic ECP and treats the remaining 14 electrons $\left[4 s^{2} p^{6} d^{5} 5 s^{1}\right]$ explicitly. Similarly, LAN2DZ ECP for Se replaces the innermost 28 electrons $\left[1 \mathrm{~s}^{2} 2 \mathrm{~s}^{2} \mathrm{p}^{6} 3 \mathrm{~s}^{2} \mathrm{p}^{6} \mathrm{~d}^{10}\right]$ in Se by a non-relativistic ECP and treats the remaining 6 electrons $\left[4 s^{2} p^{4}\right]$ explicitly. The proposed interface structures of C-O-Mo are restrictively optimized, only allowing the molybdenum, oxygen atoms (at bonding point) and two carbon atoms closest to the oxygen atom could move freely when optimization to mimic the rigid enviroment of crystal structure of $\mathrm{MoSe}_{2}$ and carbon materials. B3LYP hybrid functionals have been proved to obtain reasonable geometry structures for a variety of transition metal systems, while $\omega \mathrm{B} 97 \mathrm{XD}$ functional is well known for their accuracy in electronic structure and thermochemistry.

\section{Results and Discussions}

The formation mechanism of PVP was clearly shown in Fig. 1a. PVP with excellent solubility and wetting properties are easily attached to the surface of $\mathrm{MoSe}_{2}$, forming $\mathrm{MoSe}_{2} / \mathrm{PVP}$ hybrid nanosheets.[15] Fig. $1 \mathrm{~b}$ displays the FTIR spectrum of 
$\mathrm{MoSe}_{2} / \mathrm{PVP}$ and PVP. The peaks at $3434,2955,1661,1290 \mathrm{~cm}^{-1}$ is the characteristic peaks of $-\mathrm{OH}, \mathrm{C}-\mathrm{H}, \mathrm{C}=\mathrm{O}, \mathrm{C}-\mathrm{N}$ stretching vibration, demonstrating the successful formation of $\mathrm{MoSe}_{2} / \mathrm{PVP}$.[12] The distinctions of the CMS/FMS/PMS structures are analyzed via the XRD patterns as shown in Fig. 1a. The high purity of all the samples are observed, indexing to those of hexagonal-phase (JCPDS Card No. 29-0914). For PMS, the crystallinity of these samples is gradually lowered in the order of CMC $>$ FMS $>$ PMS. The (002) peaks of them have been shifted towards lower angels in file CMC $\left(13.68^{\circ}\right)>\operatorname{FMS}\left(12.98^{\circ}\right)>\operatorname{PMS}\left(10.0^{\circ}\right)$, suggesting the enlarged interlayer distance. According to Bragg's equation $(2 \mathrm{~d} \sin \theta=\mathrm{n} \lambda),[16]$ the $\mathrm{d}(002)$ values are calculated to $0.65,0.68$ and $0.87 \mathrm{~nm}$, respectively. Furthermore, the grain sizes $\left(\mathrm{D}_{h k l}\right)$ of FMS/PMS are 3.6, $3.4 \mathrm{~nm}$ through the utilization of the Scherrer's equation $\left(D_{h k l}=K \lambda / \beta \cos \theta\right) .[16]$ And the number of interlayers $\left(D_{h k l} / \mathrm{d}(002)\right.$ is $5.3(3.6 / 0.68)$ and $3.9(3.4 / 0.89))$, confirming that $\mathrm{MoSe}_{2}$ assisted by PVP were successfully exfoliated and expanded, derived from that the PVP insertion reduced the interlayer Van der Waals forces. After the carbonization treatment, the hybrid nanosheets could deliver an improved Li/Na-storage performance. Through the analysis of Raman spectra in Fig. 1c, the peak (marked as $\mathrm{A}_{1 \mathrm{~g}}$ ) is the exclusive peak of $\mathrm{MoSe}_{2} 2 \mathrm{H}$ structure, whilst the peaks (donated as $\mathrm{E}_{2 \mathrm{~g}}{ }^{1}, \mathrm{~J}_{2}$ ) are the characteristic peaks for 1T peaks.[17] Thus, it is concluded that PMS and CMS are composed of 1T/2H phases, and the existed 1T phase would increase metallic properties of $\mathrm{MoSe}_{2}$, which is beneficial for electrochemical properties.[18] Moreover, it is expected for PMS, that its peak at 240 
$\mathrm{cm}^{-1}$ was shifted to the lower wavenumbers, and that its peak at $280 \mathrm{~cm}^{-1}$ moves towards the higher wavenumbers, demonstrating the few-layered $\mathrm{MoSe}_{2}$ were effectively formed. [18-20] Evidentially, the peaks assigned to carbon at 1300 and $1500 \mathrm{~cm}^{-1}$ are found for PMS. The carbon content of PMS is quantified by TG as shown in Fig. 1d, and the residual product $\left(\mathrm{MoO}_{3}\right)$ is verified in the inset of Fig. 1d. Clearly, this increasing part is attributed to some of $\mathrm{MoSe}_{2}$ transforming into $\mathrm{MoO}_{3}$ and $\mathrm{SeO}_{2}$, showing the carbon content to be determined to be $\sim 10.8 \mathrm{wt} \%$.

In order to explore the chemical composition and state, PMS is analyzed by XPS. Fig. 2 and Fig. $1 \mathrm{~S}$ prove the presence of $\mathrm{M}$ cvo, Se, C, O, N elements. From the Mo core level XPS spectra in Fig. 2a, it is found that PMS is composed of 1T/2H MoSe 2 . $2 \mathrm{H}-\mathrm{MoSe}_{2}$ is associated with peaks at 232.1 and $229 \mathrm{eV}$ and $1 \mathrm{~T}-\mathrm{MoSe}_{2}$ is relation with the peaks at 231.8 and $229.2 \mathrm{eV}$, agreeing well with the analysis of Raman. Meanwhile, the content of $1 \mathrm{~T} \mathrm{MoSe}_{2}$ is calculated to be $60.3 \%$. Surprisingly, the Mo $(6+)$ peaks with binding energy is found, which demonstrates the existence of C-O-Mo.[9, 21] Note that, the peak at $237 \mathrm{eV}$ confirmed the existence of C-O-Mo bonds that is beneficial to stabilize the volume expansion and give a faster rate of electron transfer. It is deduced that the $\mathrm{C}-\mathrm{O}-\mathrm{Mo}$ comes from the carbonyl $(-\mathrm{C}=\mathrm{O})$ of PVP connected with Mo ions. Fig. 2 displayed two couples of peaks for Se 3d. The peaks located at $54 \mathrm{eV}, 56 \mathrm{eV}$ are about $3 \mathrm{~d}_{5 / 2}$ and $3 \mathrm{~d}_{3 / 2}$, respectively. Moreover, as shown in Fig. 2c, the peaks of $\mathrm{C} 1 \mathrm{~s}$ spectra at 287.8, 285.5, 284.6, $283.3 \mathrm{eV}$ are associated with $\mathrm{C}=\mathrm{O}, \mathrm{C}-\mathrm{OH} / \mathrm{C}-\mathrm{O}-\mathrm{Mo}, \mathrm{Csp} 2$ and $\mathrm{C}-\mathrm{H}$. Through the deconvolution of 
the high-resolution spectrum O1s spectra, three peaks were obtained at 532.5, 531.3, $530.5 \mathrm{eV}$, corresponding to the vibration of $\mathrm{C}=\mathrm{O}, \mathrm{C}-\mathrm{O}-\mathrm{Mo}, \mathrm{O}-\mathrm{OH}$ bonds. It is deduced that the Mo atoms at the edge of few-layer $\mathrm{MoSe}_{2}$ connected with $\mathrm{O}$ atoms from the PVP to obtain a stabilized C-O-Mo bond, which could inhibit the destruction of the structure.

To better understand the nature of the C-O-Mo bond, the first-principles calculations have been performed based on the simplified C-O-Mo interface models (as presented in Figure 3), which were assembled by the simplified models of oxidized-graphene, $\mathrm{MoSe}_{2}$ sheet fragment and oxidized-C60 fullerene (as given in Figure 2S). The calculations offered some valuable parameters (bond length, bond order, bonding energy, HOMO and LUMO), which are related to the electrochemical performance of a given structure. Frontier molecular orbitals (HOMO and LUMO) were found to be extremely valuable in the interpretation of relevant chemical reactivity. The capacity of a molecule to donate electrons is highly correlated with the HOMO. HOMO also governs the spatial distribution of valence electron mainly participating in the formation of chemical bonds, and LUMO plays an important role in explain the capacity of a molecule to accept electrons.[22] Furthermore, The HOMO-LUMO energy gap (denoted as $\Delta E_{\text {gap }}$ ) between the highest occupied molecular orbital (HOMO) and the lowest unoccupied molecular orbital (LUMO) is a valuable parameter for examining the kinetic stability of a molecule. Larger the energy gap is, better is the stability of the material. On the other hand, the binding energy of a given molecule determines its thermodynamic stability.[23]

Figure $3 \mathrm{~b}$ demonstrated S-type interface model structures in which oxidized-graphene (ox-graphene) is perpendicular to the plane of $\mathrm{MoSe}_{2}$ sheet. Here, 
it should be mentioned that in the present work, Mo, Se, C, O, H atoms are represented as small balls and colored in light blue, yellow, dark gray, red and white, respectively. It is obvious from Figure $3 b$ to see that B3LYP and $\omega$ B97XD give very similar molecular structures for the S-type interface model. The distribution of frontier orbitals from $\omega \mathrm{B} 97 \mathrm{XD}$ calculation is also analogous to that observed from B3LYP calculation. Both HOMO and LUMO are mainly localized on the $\mathrm{MoSe}_{2}$ sheet, suggesting that the interfaces structure will remain the excellent conductibility of $\mathrm{MoSe}_{2}$ nanometer material. As listed in Table 1. The HOMO-LUMO gaps calculated by B3LYP and $\omega$ B97XD are $0.72 \mathrm{eV}$ and $3.74 \mathrm{eV}$, respectively. $\omega$ B97XD included dispersion correction and could give a better electronic structure. Thus, the HOMO-LUMO gap of S-type interface model was believed to be $3.74 \mathrm{eV}$ here. It suggested the interface structure would possess good conductivity and nice kinetic stability.

On the other hand, as shown in Table 1S, the bonding energy of Mo-O in the simplified S-type interface model is $-37.3 \mathrm{kcal} / \mathrm{mol}$ from $\omega \mathrm{B} 97 \mathrm{XD}$ calculation, which is more negative than that from B3LYP calculation by $16.2 \mathrm{kcal} / \mathrm{mol}$. However, the first-principles DFT calculations with B3LYP and $\omega$ B97XD consistently predicated that Mo-O was thermodynamically favorable. Furthermore, DFT calculations with B3LYP and $\omega$ B97XD obtain very similar bond length and bond order. As displayed in Table 2S, The C-O bond length in the optimized S-type interface structure is $1.394 \AA$ $(1.388 \AA)$ from B3LYP $(\omega \mathrm{B} 97 \mathrm{XD})$ calculation, which is just slightly different from the value $1.382 \AA(1.374 \AA)$ in the optimized ox-graphene. The Mo-O bond length $(2.103$ $\AA$ ) from B3LYP is almost the same with that $(2.100 \AA)$ from $\omega \mathrm{B} 97 \mathrm{XD}$, which is close to the Mo-O bond length $(1.990 \AA)$ in Tugarinovite $\left(\mathrm{MoO}_{2}\right) \cdot[24,25]$ The C-O bond 
order in the optimized S-type interface structure is 0.830 (0.829) from B3LYP $(\omega \mathrm{B} 97 \mathrm{XD})$, which is little smaller than that of $0.914(0.915)$ in the optimized ox-graphene structure.

All these facts consistently indicated that the S-type interface structure was stable both thermodynamically and kinetically. The similar conclusions could be also derived for L-type interface model and $\mathrm{C}_{60}-\mathrm{O}-\mathrm{Mo}$ interface model. A very interesting finding is that the three simplified interfaces models give very similar HOMO-LUMO gap, C-O (Mo-O) bond length and bond order, which implied the unique C-O-Mo bond should make the hybrid materials possess a general performance (good stability and excellent conductivity). The similar results also co-support that the proposed interface models are reasonable.

The nanostructure of the CMS/FMS/PMS were analyzed by TEM, HRTEM, SAED and Mapping as shown in Fig. 4. Clearly, the large sheets of CMS, the hollow spheres of FMS and the nanospheres of PMS in Fig. 4A1-C1 are consistence well with the results of SEM (Fig. 3S). Orderly stacking of the multi-large-layers is the main constitution of the CMS structure, which reduces the mechanical stress and electron mobility.[26, 27] The relative homogeneity of PMS is observed, which is crucial for an excellent electrode material. In Fig. 4A2, some fragments attached to the surface of CMS, perhaps leading to a reduced electrochemical performance. The thin wall of FMS hollow sphere is only $35.2 \mathrm{~nm}$, which would facilitate the infiltration of electrolyte and alleviate the volume expansion to some extent. Note that, the surface of PMS nanospheres is rough and contain plenty of structural defects, ensuring the availability of plentiful active sites. According to the previous report,[28] 
the rate capacity is relation with the interparticle diffusion, which is ascribed to that lacking time renders less active sites take part in the reaction. However, the small particles would bring the surface sites distributed in a wider range of energy, which is attributed to their various energy levels. The wide distribution of active sites would be beneficial for improving the electrochemical properties of conversion-based battery materials. In Fig. 4A3-C3, the detailed structure and phase were explored through HRTEM images. It is obvious that owing to the good crystallinity, CMS shows the clear hexagonal honeycomb structure with three Se atoms surrounded one Mo atom. The lattice spacing is about 0.28 and $0.23 \mathrm{~nm}$, corresponding to the (100), (103) faces of $2 \mathrm{H}-\mathrm{MoSe}_{2} \cdot[29,30]$ In case of FMS, some $1 \mathrm{~T}-\mathrm{MoSe}_{2}$ phases are observed through that of six Se atoms bonded to one Mo atom in the partial region of the lattice fringe.[31] Note that, the nature of $1 \mathrm{~T} \mathrm{MoSe}_{2}$ is metallic, facilitating the ions transferring. Moreover, the d-spacing $(0.68 \mathrm{~nm})$ is assigned to the $(002)$ planes (MoSe 2 , JCPDS Card, No. 29-0914), and the large lattice distance in the electrolyte could provide more entrances for Li/Na-insertion/extraction.[3, 32] Expected that the (002) interlayer of the $\mathrm{MoSe}_{2}$ is successfully expanded with the assistance of the PVP, and the interlayer distance reaches to $0.90 \mathrm{~nm}$ in Fig. 4C3. The graphitic carbon (the $\mathrm{d}(002)$ of carbon, $0.34 \mathrm{~nm}$ ) was wrapped with few-layer $\mathrm{MoSe}_{2}$, which would improve the conductivity and significantly prolong the cycling stability through the utilization of potentially harmful by-products (Se, demonstrated in the following).[33] Importantly, the carbon decorated upon the lattice face was found, which originates 
from the formation of C-O-Mo between the carbonyl group (from PVP) and host Mo ions. By the comparison of their SAED images, the usual hexagonal spot pattern for CMS was clearly due to the well crystalline structure. The diffraction rings of the FMS and PMS are indexed to (002), (105) and (220) for $\mathrm{MoSe}_{2}$, and that of carbon (002) is displayed in Fig. 4C4. Moreover, the elemental mappings of PMS nanosphere reveal the homogenous distribution of $\mathrm{C}, \mathrm{N}, \mathrm{Mo}, \mathrm{Se}$ in the host structure. The structure merits of PMS, containing the unique morphology and N-doping graphite, would promote cycling stability and large rate capacity of electrode materials.[10]

The cycling capability of the as-prepared samples was explored at $1.0 \mathrm{~A} \mathrm{~g}^{-1}$ between 3.0 and $0.01 \mathrm{~V}$ as shown in Fig. 5a and 4S. PMS could deliver a high initial discharge/charge capacities of 1183 and $896 \mathrm{mAh} \mathrm{g}^{-1}$ with a coulombic efficiency (CE) of $75.7 \%$, whilst the CMS and FMS exhibited $773 / 595 \mathrm{mAh} \mathrm{g}^{-1}$ with a CE of $76.9 \%$ and $442 / 651 \mathrm{mAh} \mathrm{g}^{-1}$ with $68.9 \%$, respectively. The irreversible capacity is due to the adverse reaction and the formation of SEI film. After 150 cycles, the Li-storage capacity of CMS/FMS/PMS remained 176, 341, $1208 \mathrm{mAh} \mathrm{g}^{-1}$, and that of PMS is larger than those of previous works in Table 2. Impressively, the capacity of PMS increases gradually, that of FMS has a rise before 100 cycles but fading subsequently, and that of CMS has continuously decreased. For the continuously fading of CMS, the insulator Se-O film formed on the surface of anodes, coming from that Se ions reacted with the carbonate solvent, $[34,35]$ which would prevent the transportation of ions. For the increasing part of FMS/PMS, the in-situ generated selenide participates in the 
electrochemical reaction as the active materials.[10] For the decreasing part for FMS, overmuch Se was dissolved in the electrolyte, further deteriorating the ether-based electrolyte.[36, 37] From their differential charge capacity plots (DCPs) at 100 cycles, it is found that the peaks of CMS nearly disappear, which is ascribed to the loss of electrode activity, resulted from the serious pulverization and adverse reactions. A couple of primary reduction/oxidation peaks were located at $\sim 1.9 / 2.2 \mathrm{~V}$, and the voltage difference of FMS/PMS is $0.44 \mathrm{~V}, 0.29 \mathrm{~V}$, suggesting that the wrapped carbon plays a crucial role in the structure stabilization. According to the previous report,[10] the generation of Se was expressive, and the detailed reaction process should be illustrated clearly. For discharge process, Se is first reduced to $\mathrm{Li}_{2} \mathrm{Se}_{\mathrm{n}}(\mathrm{n}>4)$, further to $\mathrm{Li}_{2} \mathrm{Se}_{2}$ and $\mathrm{Li}_{2} \mathrm{Se}$, corresponding to the peaks at 2.0 and $0.8 \mathrm{~V}$. For charge process, $\mathrm{Li}_{2} \mathrm{Se}$ is oxidized into insoluble intermediate polyselenides $\mathrm{Li}_{2} \mathrm{Se}_{\mathrm{n}}(\mathrm{n} \geq 4)$ and $\mathrm{Se}$, where the peaks located at 1.5 and $2.2 \mathrm{~V} \cdot[34,35]$ In the DCPs of PMS at different curves for Fig. 5c, the growing peak intensity of selenium-lithiation/delithiation is obvious, adequately confirming that the content of Se is increasing upon cycling, which results in the promotion of the capacity. Moreover, in Fig. 5c, the rate stabilities for PMS were improved and the good cycling stability was displayed over the whole period. After 200 cycles, the charge capacity retained 801, 519, 453 and $277 \mathrm{mAh} \mathrm{g}^{-1}$ at 2.0, 4.0, 6.0 and $8.0 \mathrm{~A} \mathrm{~g}^{-1}$, respectively, which reveals superior large-rate cycling stability. Moreover, it is found that the increasing tendency is decreasing with the improvement of current densities, which is due to that there is not enough time for 
lithium ions reacting with electroactive sites, leading to the reduction of in-generated selenium.[28] The rate properties of the electrode samples, as the important criteria for practical application, were investigated at stepwise current densities as exhibited in Fig. 5e. Clearly, PMS delivers capacity of 1203, 1064, 956 and $865 \mathrm{mAh} \mathrm{g}^{-1}$ at 0.2 , 0.5, 1.0 and 5.0 $\mathrm{A} \mathrm{g}^{-1}$, whilst CMS and FMS display the unsatisfied performances. And the remained capacities of CMS/FMS/PMS are 1026, 188 and $78 \mathrm{mAh} \mathrm{g}^{-1}$ after all the cycles. Considering the aforementioned issues, it is concluded that the layer-by-layer carbon and C-O-Mo bonds of PMS effectively stabilize structure as well as constrain the in-situ generated Se.[35, 38] Attracted by the increasing properties of PMS, the detailed analysis was carried out. In the initial 175 cycles at $2.0 \mathrm{~A} \mathrm{~g} \mathrm{~g}^{-1}$, the capacity of PMS grew to $\sim 800 \mathrm{mAh} \mathrm{g}^{-1}$, and it remained stable in the following 25 loops, which is due to that the in-situ generated Se reached to the maximum value. Fig. 5g displays the similar charge/discharge platforms of PMS at $180^{\text {th }}, 185^{\text {th }}, 190^{\text {th }}, 195^{\text {th }}$ and $200^{\text {th }}$, suggesting the stable electrochemical reaction without extra Se generation. In Fig. 5f, the charge platforms of PMS at $2.0 \mathrm{~A} \mathrm{~g}^{-1}$ at different cycles were shown. It is found that the platforms at $2.0 \mathrm{~V}$ are stable, meanwhile, the platforms at $1.5 \mathrm{~V}$ become clear gradually, indicating that the in-situ generated Se participates in the electrochemical reaction. Fig. 5h displays the histogram of Li-storage capacity at various cycles. Obviously, the content of the in-generated Se at every cycles is almost same, and the selenium could deliver a capacity of $283 \mathrm{mAh} \mathrm{g}^{-1}$. The similar cycling behaviors were displayed at 4.0, 6.0, 8.0 
$\mathrm{A} \mathrm{g}^{-1}$, and their Li-storage capacity would remain stable in the final loops.

Further understanding of the enhanced electrochemical properties were next explored.

The Na-storage properties were analyzed between 0.01 and $3.0 \mathrm{~V}$ (Figure. 6). As clearly shown in Fig. 6a, the initial capacity of PMS was $\sim 498 / 689 \mathrm{mAh} \mathrm{g}^{-1}$ with a $\mathrm{CE}$ of $72.7 \%$ at $0.1 \mathrm{~A} \mathrm{~g}^{-1}$. After the activation process before 25 cycles, the rise of capacity was observed subsequently, similar to Li-storage behaviors. After 120 cycles, the capacity of PMS increases to $552.1 \mathrm{mAh} \mathrm{g}^{-1}$, higher than those of previous reports as summarized in Table 2. Meanwhile, PMS with the hollow structure still kept a capacity of $403.9 \mathrm{mAh} \mathrm{g}^{-1}$, but that of CMS is only $242.9 \mathrm{mAh} \mathrm{g}^{-1}$, further revealing the importance of structure design. By the comparison of discharge/charge platforms at 100 cycles in Fig. 6e, their voltages were increased in the order of CMS $>$ FMS $>$ PMS, indicating the facile electrochemical reaction for PMS. Accompanying with the charge-discharge process, the Se atoms of chain-like Se would form a stronger interaction with the carbon substrate, thereby constrained in the carbon layer. From the rate capability in Fig. 6b, the excellent property of PMS was exhibited, delivering a capacity of $417,390,367,353$ and $339 \mathrm{mAh} \mathrm{g}^{-1}$ at $0.1,0.2,0.5,1.0,2.0$ and $5.0 \mathrm{~A}$ $\mathrm{g}^{-1}$, respectively. When the current density reduced to $0.1 \mathrm{~A} \mathrm{~g}^{-1}$, a capacity of $518 \mathrm{mAh}$ $\mathrm{g}^{-1}$ is still recovered. With the cycling at $1.0 \mathrm{~A} \mathrm{~g}^{-1}$, its capacity is about $491 \mathrm{mAh} \mathrm{g}^{-1}$ at $100^{\text {th }}$ cycle. Fig. 6c presents the comparison of large-current cycling stability for CMS/FMS/PMS, where the capacity of PMS can reach to $529 \mathrm{mAh} \mathrm{g}^{-1}$ after 120 cycles at $1.0 \mathrm{~A} \mathrm{~g}^{-1}$, which is ascribed to its stable structure and in-situ generated Se. In 
Fig. 5S, the longer cycling of PMS was displayed and the maximum capacity could reach to $\sim 570 \mathrm{mAh} \mathrm{g}^{-1}$, and it kept stable in the following cycles (from $200^{\text {th }}$ to $250^{\text {th }}$ ). The capacity of FMS kept stability before 80 cycles and fades subsequently, resulted from the destruction of the structure coming from fast Na-insertion/extraction and the dissolution of selenium. Moreover, from the ex-situ SEM of the electrodes and separators over 100 cycles in Fig. 5S, it is obvious that the small size of particle facilitates samples stable upon the $\mathrm{Cu}$ foils, which is beneficial for the electrochemical properties. Over the whole period, it is clear that the capacity of PMS kept at $\sim 446,348,261$ and 244 over current densities of 2.0, 4.0, 6.0 and $8.0 \mathrm{~A} \mathrm{~g}^{-1}$, and this increasing capacity phenomenon is stilled observed. With the increasing of current densities, the growth tendency of capacity is reducing, agreeing well with the Li-storage behaviors. Through the comparison of DCPs at $2^{\text {nd }}, 30^{\text {th }}, 60^{\text {th }} 100^{\text {th }}$ cycles, the rising capacity region was mainly located at $2.0 \sim 3.0 \mathrm{~V}$. Recent report demonstrates that Se was produced in $\sim 2.3 \mathrm{~V}$ for $\mathrm{MoSe}_{2}$, which is corresponding to the reaction $\left(\mathrm{Na}_{2} \mathrm{Se}+2 \mathrm{e}^{-} \rightarrow 2 \mathrm{Na}+\mathrm{Se}\right)$, which was further demonstrated by ex-situ XRD in Fig. 7S. [10] Effectively confined by the carbon shell with C-O-Mo bonds, the in-situ generated Se plays multi-roles expected roles for the $\mathrm{MoSe}_{2}$ materials: (1) the active materials for the high capacity; (2) the conductive agent for the rate performance. $[33,39]$ Moreover, the electrochemical properties of commercial pure selenium for LIBs/SIBs were investigated and displayed in Fig. 6S. It is obvious that the cycling were fading seriously without the protection of effective carbon layer 
The point that the in-situ generated Se leads to the increasing capacity was further supported and evaluated in the Fig. 7. As clearly exhibited in Fig. 7a for the charge curves of different cycles $\left(2^{\text {nd }}, 20^{\text {th }}, 40^{\text {th }}, 60^{\text {th }}, 80^{\text {th }}, 100^{\text {th }}, 120^{\text {th }}\right)$, the curves below $1.8 \mathrm{~V}$ are close to overlapping, whilst those in the range of $1.8-3.0 \mathrm{~V}$ are gradually flat, indicating that the rising capacity derives from the electrochemical reaction above $1.8 \mathrm{~V}$. Thus, the capacity in different voltage ranges were exhibited in Figure. 7(b), the capacity contributions for different cycles between 0.01 and $1.8 \mathrm{~V}$ keep constant and remain at $\sim 250 \mathrm{mAh} \mathrm{g}^{-1}$, but those above $1.8 \mathrm{~V}$ increase from 173 to $265 \mathrm{mAh} \mathrm{g}^{-1}$. Two reasons can be concluded: (1) the capacity from host conversion reaction $\left(\mathrm{Na}_{2} \mathrm{Se}+\mathrm{Mo}+2 \mathrm{e}^{-} \rightarrow 2 \mathrm{Na}+\mathrm{MoSe}_{2}\right)$ is almost same, indicating the stable Na-capacity contribution of $\mathrm{MoSe}_{2}$; (2) the portion from the emerging conversion reaction $\left(\mathrm{Na}_{2} \mathrm{Se}+2 \mathrm{e}^{-} \rightarrow 2 \mathrm{Na}+\mathrm{Se}\right)$ is increasing, indicating that more in-generated $\mathrm{Se}$ participate the sodiation/desodiation reactions upon repeated cycling. The contribution of the Se is about $92 \mathrm{mAh} \mathrm{g}^{-1}$, approaching to $20 \%$ of total capacity, which activate PMS take part in the electrochemical reaction completely. The CV curves at the scan rate of $5.0 \mathrm{mV} \mathrm{s}^{-1}$ were displayed in Fig. 7(c). The gradually enlarged areas agree well with the cycling performance. Owing to two kinds of conversion reactions, the reduction peaks at $1.5 \mathrm{~V}$ slowly separated into two peaks. Meanwhile, the oxidation peak at $\sim 2.3 \mathrm{~V}$ appeared more distinctly and moved towards high voltages, demonstrating that new substance was generated in the high oxidation region. The ex-situ Raman spectra of PMS after different cycles present a clear 
evolution of the Se. The broad peak at $250 \mathrm{~cm}^{-1}$ appears, which are indexed to amorphous Se comprised of $\mathrm{Se}_{\mathrm{n}}$ chain at $252 \mathrm{~cm}^{-1}$.[37, 40] With cycling, the intensity of peak becomes strong, representing the augmentation of Se hybrid. Note that, a strong interaction was produced between carbon substrate and the chain-like $\mathrm{Se}_{\mathrm{n}}$, successfully confining Se in the carbon matrix, which is in favor of improving the cycling stability and rate capability.[31]

Fig. 8 demonstrates the ex-situ TEM, HRTEM, SAED of PMS after recharging to 3.0 $\mathrm{V}$ at the $100^{\text {th }} \mathrm{Na}$-insertion/extraction cycle at $0.1 \mathrm{~A} \mathrm{~g}^{-1}$, clearly revealing the variations of structure and components. As clearly exhibited in Fig. 8, the structure of CMS has a serious pulverization. Meanwhile, the hollow structure of FMS effectively alleviated the volume swelling, but some fragments were still observed. The stable structure of PMS was observed, which further demonstrates its advantages of the designed structure. In Fig. 8A2-C2, the emergence of a large shadow was found for CMS and these shadowed dots were distributed in the fragments of FMS, implying that the by-products (containing $\mathrm{Se}, \mathrm{Mo}$ ) from the $\mathrm{MoSe}_{2}$ are aggregated seriously. By contrast, no obvious dots were found for PMS, which suggests that the by-products Se were uniformly confined in the carbon. In the HRTEM images, the calculated lattice distance of FMS is $\sim 0.70 \mathrm{~nm}$, which is assigned to the (002) face of the $\mathrm{MoSe}_{2}$. And the enlarged lattice fringes are attributed to the expansion resulted from the insertion of $\mathrm{Na}^{+}$. In Fig. 8A3, the lattice for the Mo structure is not detected but confirmed through the weak diffraction ring of Mo (226), which was ascribed to the losing of 
Mo-containing ions in the electrolyte. Expectedly, in Fig. 8B3, the lattice fringes with a d-distance $(0.21 \mathrm{~nm})$ corresponds to the (226) planes of Mo (JCPDs Card: 88-2331), which reveal that some Se from $\mathrm{MoSe}_{2}$ were produced.[10] Importantly, the Se was detected to scatter homogeneously in the carbon matrix, confirming that carbon layer effectively confined the Se, which is beneficial for improving capacity and conductivity. For the SAED images of PMS in Fig. 8C4, the presence of diffraction rings about Mo (226), $\mathrm{MoSe}_{2}$ (002), (100) and (220) is the evidence of generated Mo, and $\mathrm{MoSe}_{2}$. It is concluded that the similar reaction for the as-obtained electrodes, but the rational design of the structure is vital for confining the in-situ generated Se.

In Fig. 9, the CV curves of PMS and FMS as LIBs/SIBs batteries were displayed. Clearly, the first cycle is distinctly different from other cycles, which is ascribed to the formation of SEI (solid electrolyte interface) film and some side reactions. In Fig. 9A1, A2, CV curves of PMS/FMS as LIBs anodes at $0.1 \mathrm{mV} \mathrm{s}^{-1}$ were shown and it is found that $2^{\text {nd }}$ and $3^{\text {rd }}$ curves keep consistence, suggesting the cycling stability at initial part. In the comparison of their $3^{\text {rd }}$ cycles in Fig. 9. A3, the appeared peak of FMS at $1.5 \mathrm{~V}$ is relation with the phase transform $\left(\mathrm{Li}_{2} \mathrm{Se} \rightarrow \mathrm{Li}_{2} \mathrm{Se}_{\mathrm{n}}+\mathrm{Se}\right)$. [34] And the other peak $\left(\mathrm{Li}_{2} \mathrm{Se} \rightarrow \mathrm{Li}_{2} \mathrm{Se}_{\mathrm{n}}+\mathrm{Se}\right)$ at $2.2 \mathrm{~V}$ maybe overlapped with the peak $\left(\mathrm{Li}_{2} \mathrm{Se}\right.$ with Mo was converted to $\mathrm{MoSe}_{2}$ ). Meanwhile, the peak of PMS at $1.5 \mathrm{~V}$ is not clear, demonstrating that the C-O-Mo bonds could promote the reversible conversion at initial cycling.[21] Obviously, in Fig. 9B1, B2, the position of redox peaks were shifted to low voltage, resulted from the sluggish sodium kinetic. The peak at $2.26 \mathrm{~V}$ 
is due to the in-situ generated Se, which has been demonstrated by the previous report, [10] illustrating that the reversible conversion for SIBs is uncontrolled by C-O-Mo bonds. According to the key work,[1] the Se could be further stabilized in the carbon matrix. Note that the peak of PMS is broadened as compared to that of FMS. The phenomenon was rationally illustrated.[28] Theoretically, the equal active sites would require the same energy, giving rise to a sharp peak. However, the electroactivity of sites is distributed in a range, resulting the wide peak. With the reduction of particle size, the increased electroactive sites would lead to the broad distribution of redox site energies. Obviously, the competition between the neighboring redox centers to participate in the redox reaction would be less, which could improve charge/discharge rate. It is concluded that the decreasing particle is the fundamental reason for high-rate performance.

For further investigating the interfacial properties of the PMS, EIS was carried out to evaluate the evolution of surface as displayed in Fig. 9B and Fig. 9S. From the initial Nyquist plots of the as-obtained samples in Fig. 9S, the curve is composed of two parts: (1) the depressed semicircles in the high frequency corresponds to the active materials/electrolyte resistance; (2) a slow line at low frequency is relation with the Warburg impedance. The smaller particles with a larger area connecting with electrolyte could lessen the resistance, and the existing carbon leads to the further reduction of resistance. The subsequent EIS (the $20^{\text {th }}$ and $80^{\text {th }}$ cycles for LIBs, the $10^{\text {th }}$ and $40^{\text {th }}$ for SIBs) are shown with fitting line as well as corresponding equivalent 
circuit modeling in Fig. 9B2 and B3, revealing the similar interfacial behavior. Obviously, owing to the better kinetic coefficient of $\mathrm{Li}^{+}$, the smaller resistance is clearly exhibited compared to that for SIBs. And the drastically decreasing resistance demonstrates the formation of by-products, which could enhance electronic conductivity. Moreover, after some cycles, the EIS curves exhibit two depressed semicircles in the high and middle frequency middle, suggesting the emerging of new interfacial resistance. According to the excellent fitting lines, the equivalent circuit modeling is available, in which $\mathrm{R}_{1}$ is the electrolyte resistance form the bulk, separator, electrode, $\mathrm{R}_{2}$ is about the charge transfer resistance in the carbon shell and SEI film interface/electrolyte for PMS (S1, [R2, CPE1]), R3 is the charge transfer resistance in the interface of $\mathrm{MoSe}_{2}$ grains/electrolyte (S2, [R3, CPE2]). Through the simplified models of PMS in Fig. 9B3, the interfacial resistance between carbon and materials was illustrated clearly, whilst the function of the emerging intermediates can be observed directly. In this model, the carbon/electrolyte interfacial and the interfacial SEI electrolyte interfacial are defined S1. The electrolyte that infiltrates in the internal structure of PMS through the plentiful defects and microporous, could form the S2 interface that composed of Se, Se-O species.[39] Owing to the improved conductivity from the in-situ generated Se, the impendences were decreased, whilst the diffusion coefficients were increased gradually in Fig. 10S. All the fitting data of EIS are recorded in Table 3 and Fig. 11S, and the Faradic current density ( $\left.\mathrm{I}_{\mathrm{F}}\right)$ of S1 and the diffusion coefficient (D) of PMS are calculated, obeying the following 
Equation 1-3.

$Z=R+\sigma w^{-0.5}$

$I_{F}=R T / n A F R_{2}$

$D=0.5 R^{2} T^{2} / S^{2} n^{4} F^{4} C^{2} \sigma^{2}$

Clearly, with cycling, the value R2 of resistance reduced from 52 to $33 \Omega$ for LIBs, 191 to $57 \Omega$ for SIBs, accompanied by its space charge capacitance CPE1 dropping from $3.8 \times 10^{-4}$ to $1.7 \times 10^{-4} \mathrm{~F}$ for LIBs, $1.6 \times 10^{-4}$ to $1.1 \times 10^{-4} \mathrm{~F}$ for SIBs, resulted from that more charge aggregated at interface $\mathrm{S} 1$ would reduce the resistance. Moreover, the value of $\mathrm{I}_{\mathrm{F}}$ increases from $3.29 \times 10^{-4}$ to $7.41 \times 10^{-4} \mathrm{~mA} \mathrm{~cm}^{-2}$ for LIBs, $8.55 \times 10^{-5}$ to $3.28 \times 10^{-4} \mathrm{~mA} \mathrm{~cm}^{-2}$. Based upon the previous report, the formation of dense and complete SEI film would improve the conductivity of interfacial carrier, which is beneficial for the generation of pseudo-capacitance during the $\mathrm{Li}^{+} / \mathrm{Na}^{+}$ insertion/extraction.[41] Furthermore, the reduction of D as recorded in Table 3 and Fig. 11S demonstrate that the emerging by-products possess the high conductivity, facilitating the fast electron transfer. Note that, the formation of dual-capacitive interface would be in favor of the charge accumulation on the interface, inducing the deep insertion the host structure and increasing the diffusion ability of $\mathrm{Li}^{+} / \mathrm{Na}^{+}$ions, thereby improving the electrochemical performances.[42]

\section{Conclusion}

In summary, the exfoliated $\mathrm{MoSe}_{2}$ constrained inside $\mathrm{C}$ nanospheres with the uniform diameter of $100 \mathrm{~nm}$ were successfully prepared through the assistance of the dual 
roles of PVP, bringing the large lattice distance of (002) face and few-layers structure. The first-principles DFT calculations predicted that the unique C-O-Mo bond should make the hybrid materials possess general performance (good stability and excellent conductivity). Utilized as anodes for LIBs/SIBs, besides the stable capacity of host materials $\mathrm{MoSe}_{2}$, the significant design with C-O-Mo binding would act an important role in anchoring and activating the in-situ generated of Se, effectively lowering the adverse reaction, accompanying with the improved capacity stability and rate properties. For LIBs, after cycling, the capacity can be kept about $801,549 \mathrm{mAh} \mathrm{g}^{-1}$ at 2.0, 4.0 $\mathrm{A} \mathrm{g}^{-1}$, respectively. For SIBs, the remained capacity is about $441,348 \mathrm{mAh} \mathrm{g}^{-1}$ at $1.0,4.0 \mathrm{~A} \mathrm{~g}^{-1}$ after 120 cycles. Ex-situ Raman and HRTEM confirmed that the as-formed $\mathrm{Se}$ is restrained by the effective structure, which is distributed homogeneously through the chain-like $\mathrm{Se}_{\mathrm{n}}$ molecule strongly interacted with the carbon. Through the quantitative analysis of CV and EIS, the reduction of particle size with in-situ generate Se could improve the charge-discharge rate and conductivity of dual-capacitive, which are deemed as the fundamental reason for the excellent electrochemical properties. This work opens up a wide avenue to the design of $2 \mathrm{D}$ TMDs as anodes for LIBs/SIBs, and enhances in-depth understanding of the effect about the in-situ generated Se on the energy-storage behaviors of metal-selenide, whilst bringing new investigating strategy on the metal-based materials.

\section{ACKNOWLEDGMENT}

This work was financially supported by National Natural Science Foundation of 
China (51622406, 21673298 and 21473258), Innovation Mover Program of Central South University (2016CX020), Distinguished Young Scientists of Hunan Province (13JJ1004), the Fundamental Research Funds for the Central Universities of Central South University (2016zzts022) and the Startup Fund of Central South University for Young Teachers (502044001). This work was carried out in part using hardware and/or software provided by Tianhe II supercomputer in National Supercomputing Center in Guangzhou, the High-Performance Computing Centers of Central South University and Nanjing University. The staff from Supercomputing Center and High-Performance Computing Centers, and the engineers from Beijing Paratera Technology Co., Ltd. provided effective support and made the computation smoothly during the course. Sincere gratitude must be given to them.

Appendix A. Supporting information

Supplementary data associated with this article can be found in the online at ***

\section{Reference}

[1] A. Eftekhari, The rise of lithium-selenium batteries, Sustainable Energy \& Fuels, 1 (2017) 14-29.

[2] A. Eftekhari, Molybdenum diselenide $\left(\mathrm{MoSe}_{2}\right)$ for energy storage, catalysis, and optoelectronics, Applied Materials Today, 8 (2017) 1-17.

[3] W. Tang, D. Xie, T. Shen, X. Wang, D. Wang, X. Zhang, X. Xia, J. Wu, J. Tu, Construction of Nitrogen-Doped Carbon-Coated $\mathrm{MoSe}_{2}$ Microspheres with Enhanced Performance for Lithium Storage, Chemistry, 23 (2017) 12924-12929.

[4] J. Wang, C. Peng, L. Zhang, Y. Fu, H. Li, X. Zhao, J. Zhu, X. Wang, Construction 
of N-doped carbon@MoSe 2 core/branch nanostructure via simultaneous formation of core and branch for high-performance lithium-ion batteries, Electrochim. Acta., 256 (2017) 19-27.

[5] T. Chen, Z. Zhang, B. Cheng, R. Chen, Y. Hu, L. Ma, G. Zhu, J. Liu, Z. Jin, Self-Templated Formation of Interlaced Carbon Nanotubes Threaded Hollow $\mathrm{Co}_{3} \mathrm{~S}_{4}$ Nanoboxes for High-Rate and Heat-Resistant Lithium-Sulfur Batteries, J. Am. Chem. Soc., 139 (2017) 12710-12715.

[6] H. Wang, L. Wang, X. Wang, J. Quan, L. Mi, L. Yuan, G. Li, B. Zhang, H. Zhong, Y. Jiang, High Quality $\mathrm{MoSe}_{2}$ Nanospheres with Superior Electrochemical Properties for Sodium Batteries, J. Electroanal. Chem., 163 (2016) A1627-A1632.

[7] B. Chen, Y. Meng, F. He, E. Liu, C. Shi, C. He, L. Ma, Q. Li, J. Li, N. Zhao, Thermal decomposition-reduced layer-by-layer nitrogen-doped graphene/ $\mathrm{MoS}_{2} /$ nitrogen-doped graphene heterostructure for promising lithium-ion batteries, Nano Ener., 41 (2017) 154-163.

[8] F. Niu, J. Yang, N. Wang, D. Zhang, W. Fan, J. Yang, Y. Qian, MoSe 2 -Covered N,P-Doped Carbon Nanosheets as a Long-Life and High-Rate Anode Material for Sodium-Ion Batteries, Adv. Funct. Mater., 27 (2017) 1700522.

[9] T. Xiang, S. Tao, W. Xu, Q. Fang, C. Wu, D. Liu, Y. Zhou, A. Khalil, Z. Muhammad, W. Chu, Z. Wang, H. Xiang, Q. Liu, L. Song, Stable 1T-MoSe 2 and Carbon Nanotube Hybridized Flexible Film: Binder-Free and High-Performance Li-Ion Anode, ACS Nano, 11 (2017) 6483-6491.

[10] F. Niu, J. Yang, N. Wang, D. Zhang, W. Fan, J. Yang, Y. Qian, MoSe 2 -Covered N,P-Doped Carbon Nanosheets as a Long-Life and High-Rate Anode Material for Sodium-Ion Batteries, Adv. Funct. Mater., 27 (2017).

[11] X. Zhang, Z. Lai, C. Tan, H. Zhang, Solution-Processed Two-Dimensional MoS 2 Nanosheets: Preparation, Hybridization, and Applications, Angew. Chem. Int. Ed., 55 (2016) 8816-8838.

[12] C. Dai, Z. Zhou, C. Tian, Y. Li, C. Yang, X. Gao, X. Tian, Large-Scale Synthesis 
of Graphene-Like $\mathrm{MoSe}_{2}$ Nanosheets for Efficient Hydrogen Evolution Reaction, J. Phys. Chem. C, 121 (2017) 1974-1981.

[13] Z. Lei, W. Zhu, S. Xu, J. Ding, J. Wan, P. Wu, Hydrophilic MoSe 2 Nanosheets as Effective Photothermal Therapy Agents and Their Application in Smart Devices, ACS Appl. Mater. Interfaces., 8 (2016) 20900-20908.

[14] S. Zhang, J. Li, E. Wang, Ultrafine transition metal dichalcogenide nanodots prepared by polyvinylpyrrolidone-assisted liquid phase exfoliation, J. Mater. Chem. B, 5 (2017) 2609-2615.

[15] J. Liu, Z. Zeng, X. Cao, G. Lu, L.H. Wang, Q.L. Fan, W. Huang, H. Zhang, Preparation of $\mathrm{MoS}_{2}$-polyvinylpyrrolidone nanocomposites for flexible nonvolatile rewritable memory devices with reduced graphene oxide electrodes, Small, 8 (2012) $3517-3522$.

[16] Y. Cao, L. Xiao, M.L. Sushko, W. Wang, B. Schwenzer, J. Xiao, Z. Nie, L.V. Saraf, Z. Yang, J. Liu, Sodium ion insertion in hollow carbon nanowires for battery applications, Nano Lett, 12 (2012) 3783-3787.

[17] B. Xia, T. Wang, W. Xiao, R. Zhang, P. Liu, J. Ding, D. Gao, D. Xue, Phase-transfer induced room temperature ferromagnetic behavior in 1T@2 $\mathrm{H}-\mathrm{MoSe}_{2}$ nanosheets, Sci. Rep., 7 (2017) 45307.

[18] J.B. Cook, H.-S. Kim, Y. Yan, J.S. Ko, S. Robbennolt, B. Dunn, S.H. Tolbert, Mesoporous $\mathrm{MoS}_{2}$ as a Transition Metal Dichalcogenide Exhibiting Pseudocapacitive Li and Na-Ion Charge Storage, Adv. Energy Mater., 6 (2016) 1501937.

[19] M. Zhuang, Y. Ding, X. Ou, Z. Luo, Polymer-confined growth of perforated $\mathrm{MoSe}_{2}$ single-crystals on N-doped graphene toward enhanced hydrogen evolution, Nanoscale, 9 (2017) 4652-4659.

[20] M.-H. Wu, J.-T. Lee, Y.J. Chung, M. Srinivaas, J.-M. Wu, Ultrahigh efficient degradation activity of single- and few-layered $\mathrm{MoSe}_{2}$ nanoflowers in dark by piezo-catalyst effect, Nano Ener., 40 (2017) 369-375.

[21] X. Zhao, H.-E. Wang, Y. Yang, Z.G. Neale, R.C. Massé, J. Cao, W. Cai, J. Sui, G. 
Cao, Reversible and fast Na-ion storage in $\mathrm{MoO}_{2} / \mathrm{MoSe}_{2}$ heterostructures for high energy-high power Na-ion capacitors, Energy Storage Mater., 12 (2018) 241-251.

[22] P. Chen, Y. Hu, Z. Gao, J. Zhai, D. Fang, T. Yue, C. Zhang, W. Sun, Discovery of a Novel Cationic Surfactant: Tributyltetradecyl-Phosphonium Chloride for Iron Ore Flotation: From Prediction to Experimental Verification, Minerals, 7 (2017) 240.

[23] L.P. Ding, F.H. Zhang, Y.S. Zhu, C. Lu, X.Y. Kuang, J. Lv, P. Shao, Understanding the structural transformation, stability of medium-sized neutral and charged silicon clusters, Sci. Rep., 5 (2015).

[24] M.G. Brik, I. Sildos, V. Kiisk, First-principles calculations of optical and electronic properties of pure and $\mathrm{Sm}^{3+}$-doped $\mathrm{TiO}_{2}$, Physica B-Condensed Matter, 405 (2010) 2450-2456.

[25] R.T. Downs, M. Hall-Wallace, The American mineralogist crystal structure database, American Mineralogist, 88 (2003) 247-250.

[26] G. Li, D. Luo, X. Wang, M.H. Seo, S. Hemmati, A. Yu, Z. Chen, Enhanced Reversible Sodium-Ion Intercalation by Synergistic Coupling of Few-Layered $\mathrm{MoS}_{2}$ and S-Doped Graphene, Adv. Funct. Mater., 27 (2017).

[27] X. Li, Y. Yang, J. Liu, L. Ouyang, J. Liu, R. Hu, L. Yang, M. Zhu, $\mathrm{MoS}_{2} /$ cotton-derived carbon fibers with enhanced cyclic performance for sodium-ion batteries, Applied Surface Science, 413 (2017) 169-174.

[28] A. Eftekhari, M. Mohamedi, Tailoring pseudocapacitive materials from a mechanistic perspective, Mater. Today Energy, 6 (2017) 211-229.

[29] Y. Gong, G. Ye, S. Lei, G. Shi, Y. He, J. Lin, X. Zhang, R. Vajtai, S.T. Pantelides, W. Zhou, B. Li, P.M. Ajayan, Synthesis of Millimeter-Scale Transition Metal Dichalcogenides Single Crystals, Adv. Funct. Mater., 26 (2016) 2009-2015.

[30] M.K. Cheng, J. Liang, Y.H. Lai, L.X. Pang, Y. Liu, J.Y. Shen, J.Q. Hou, Q. Lin He, B.C. Xu, J.S. Chen, G. Wang, C. Liu, R. Lortz, I.K. Sou, Large-area epitaxial growth of MoSe2 via an incandescent molybdenum source, Nanotechnology, 28 (2017) 455601. 
[31] X. Wang, X. Shen, Z. Wang, R. Yu, L. Chen, Atomic-Scale Clarification of Structural Transition of $\mathrm{MoS}_{2}$ upon Sodium Intercalation, Acs Nano, 8 (2014) 11394-11400.

[32] J. Li, H. Hu, F. Qin, P. Zhang, L. Zou, H. Wang, K. Zhang, Y. Lai, Flower-like MoSe2 /C Composite with Expanded (002) Planes of Few-layer $\mathrm{MoSe}_{2}$ as the Anode for High-Performance Sodium-Ion Batteries, Chemistry, 23 (2017) 14004-14010.

[33] J. Ding, H. Zhou, H. Zhang, T. Stephenson, Z. Li, D. Karpuzov, D. Mitlin, Exceptional energy and new insight with a sodium-selenium battery based on a carbon nanosheet cathode and a pseudographite anode, Energy Environ. Sci., 10 (2017) 153-165.

[34] Y. Cui, A. Abouimrane, J. Lu, T. Bolin, Y. Ren, W. Weng, C. Sun, V.A. Maroni, S.M. Heald, K. Amine, (De)lithiation mechanism of $\mathrm{Li} / \mathrm{SeS}_{\mathrm{x}}(\mathrm{x}=0-7)$ batteries determined by in situ synchrotron X-ray diffraction and X-ray absorption spectroscopy, J. Am. Chem. Soc., 135 (2013) 8047-8056.

[35] A. Abouimrane, D. Dambournet, K.W. Chapman, P.J. Chupas, W. Weng, K. Amine, A new class of lithium and sodium rechargeable batteries based on selenium and selenium-sulfur as a positive electrode, J. Am. Chem. Soc., 134 (2012) 4505-4508.

[36] H. Zhang, D. Jia, Z. Yang, F. Yu, Y. Su, D. Wang, Q. Shen, Alkaline lignin derived porous carbon as an efficient scaffold for lithium-selenium battery cathode, Carbon, 122 (2017) 547-555.

[37] C.-P. Yang, S. Xin, Y.-X. Yin, H. Ye, J. Zhang, Y.-G. Guo, An Advanced Selenium-Carbon Cathode for Rechargeable Lithium-Selenium Batteries, Angew. Chem. Int. Ed., 52 (2013) 8363-8367.

[38] K. Han, Z. Liu, J. Shen, Y. Lin, F. Dai, H. Ye, A Free-Standing and Ultralong-Life Lithium-Selenium Battery Cathode Enabled by 3D Mesoporous Carbon/Graphene Hierarchical Architecture, Adv. Funct. Mater., 25 (2015) 455-463.

[39] C. Luo, Y. Xu, Y. Zhu, Y. Liu, S. Zheng, Y. Liu, A. Langrock, C. Wang, 
Selenium@Mesoporous Carbon Composite with Superior Lithium and Sodium Storage Capacity, Acs Nano, 7 (2013) 8003-8010.

[40] H. Ye, Y.-X. Yin, S.-F. Zhang, Y.-G. Guo, Advanced Se-C nanocomposites: a bifunctional electrode material for both $\mathrm{Li}-\mathrm{Se}$ and Li-ion batteries, J. Mater. Chem. A, $2(2014) 13293$.

[41] T. Xia, W. Zhang, J. Murowchick, G. Liu, X. Chen, Built-in Electric Field-Assisted Surface-Amorphized Nanocrystals for High-Rate Lithium-Ion Battery, Nano Letters, 13 (2013) 5289-5296.

[42] H. Huang, S. Gao, A.-M. Wu, K. Cheng, X.-N. Li, X.-X. Gao, J.-J. Zhao, X.-L. Dong, G.-Z. Cao, $\mathrm{Fe}_{3} \mathrm{~N}$ constrained inside $\mathrm{C}$ nanocages as an anode for Li-ion batteries through post-synthesis nitridation, Nano Ener., 31 (2017) 74-83.

[43] C. Cui, G. Zhou, W. Wei, L. Chen, C. Li, J. Yue, Boosting sodium-ion storage performance of $\mathrm{MoSe}_{2} @ \mathrm{C}$ electrospinning nanofibers by embedding graphene nanosheets, J. Alloys Compd., 727 (2017) 1280-1287.

[44] R. Jin, Y. Cui, Q. Wang, G. Li, Facile fabrication of CNTs@C@MoSe $@ @ S e$ hybrids with amorphous structure for high performance anode in lithium-ion batteries, J. Colloid Interface Sci., 508 (2017) 435-442.

[45] G. Jia, H. Wang, D. Chao, H. He, N.H. Tiep, Y. Zhang, Z. Zhang, H.J. Fan, Ultrathin $\mathrm{MoSe}_{2} @ \mathrm{~N}$-doped carbon composite nanospheres for stable Na-ion storage, Nanotechnology, 28 (2017) 42LT01.

[46] C. Zheng, C. Chen, L. Chen, M. Wei, A CMK-5-encapsulated MoSe 2 composite for rechargeable lithium-ion batteries with improved electrochemical performance, J. Mater. Chem. A, 5 (2017) 19632-19638.

[47] G.D. Park, J.H. Kim, S.K. Park, Y.C. Kang, $\mathrm{MoSe}_{2}$ Embedded CNT-Reduced Graphene Oxide Composite Microsphere with Superior Sodium Ion Storage and Electrocatalytic Hydrogen Evolution Performances, ACS Appl Mater Interfaces, 9 (2017) 10673-10683.

[48] D. Xie, X. Xia, Y. Zhong, Y. Wang, D. Wang, X. Wang, J. Tu, Exploring 
Advanced Sandwiched Arrays by Vertical Graphene and N-Doped Carbon for Enhanced Sodium Storage, Adv. Energy Mater., 7 (2017).

[49] Y. Tang, Z. Zhao, Y. Wang, Y. Dong, Y. Liu, X. Wang, J. Qiu, Carbon-Stabilized Interlayer-Expanded Few-Layer $\mathrm{MoSe}_{2}$ Nanosheets for Sodium Ion Batteries with Enhanced Rate Capability and Cycling Performance, ACS Appl Mater Interfaces, 8 (2016) 32324-32332.

[50] X. Yang, Z. Zhang, X. Shi, Rational design of coaxial-cable $\mathrm{MoSe}_{2} / \mathrm{C}$ : Towards high performance electrode materials for lithium-ion and sodium-ion batteries, J. Alloys Compd., 686 (2016) 413-420.

[51] X. Zhao, J. Sui, F. Li, H. Fang, H. Wang, J. Li, W. Cai, G. Cao, Lamellar $\mathrm{MoSe}_{2}$ nanosheets embedded with $\mathrm{MoO}_{2}$ nanoparticles: novel hybrid nanostructures promoted excellent performances for lithium ion batteries, Nanoscale, 8 (2016) 17902-17910.

[52] B. Mendoza-Sánchez, J. Coelho, A. Pokle, V. Nicolosi, A study of the charge storage properties of a $\mathrm{MoSe}_{2}$ nanoplatelets/SWCNTs electrode in a $\mathrm{Li}$-ion based electrolyte, Electrochim. Acta., 192 (2016) 1-7.

[53] Z. Luo, J. Zhou, L. Wang, G. Fang, A. Pan, S. Liang, Two-dimensional hybrid nanosheets of few layered $\mathrm{MoSe}_{2}$ on reduced graphene oxide as anodes for long-cycle-life lithium-ion batteries, J. Mater. Chem. A, 4 (2016) 15302-15308.

[54] H. Wu, Y. Wu, X. Chen, Y. Ma, M. Xu, W. Wei, J. Pan, X. Xiong, Rational design and preparation of few-layered $\mathrm{MoSe}_{2}$ nanosheet@ $\mathrm{C} / \mathrm{TiO}_{2}$ nanobelt heterostructures with superior lithium storage performance, RSC Adv., 6 (2016) 23161-23168.

[55] S.H. Choi, Y.C. Kang, Fullerene-like $\mathrm{MoSe}_{2}$ nanoparticles-embedded CNT balls with excellent structural stability for highly reversible sodium-ion storage, Nanoscale, 8 (2016) 4209-4216.

[56] Z. Zhang, Y. Fu, X. Yang, Y. Qu, Z. Zhang, Hierarchical $\mathrm{MoSe}_{2}$ Nanosheets/Reduced Graphene Oxide Composites as Anodes for Lithium-Ion and Sodium-Ion Batteries with Enhanced Electrochemical Performance, ChemNanoMat, 1 
(2015) 409-414.

[57] Y.Y. Lee, G.O. Park, Y.S. Choi, J.K. Shon, J. Yoon, K.H. Kim, W.-S. Yoon, H. Kim, J.M. Kim, Mesoporous transition metal dichalcogenide $\mathrm{ME}_{2}(\mathrm{M}=\mathrm{Mo}, \mathrm{W} ; \mathrm{E}=\mathrm{S}$, Se) with 2-D layered crystallinity as anode materials for lithium ion batteries, RSC Adv., 6 (2016) 14253-14260.

[58] Y. Zhang, Z. Liu, H. Zhao, Y. Du, $\mathrm{MoSe}_{2}$ nanosheets grown on carbon cloth with superior electrochemical performance as flexible electrode for sodium ion batteries, RSC Adv., 6 (2016) 1440-1444.

[59] H. Wang, X. Lan, D. Jiang, Y. Zhang, H. Zhong, Z. Zhang, Y. Jiang, Sodium storage and transport properties in pyrolysis synthesized $\mathrm{MoSe}_{2}$ nanoplates for high performance sodium-ion batteries, J. Power Sources., 283 (2015) 187-194.

[60] J. Yao, B. Liu, S. Ozden, J. Wu, S. Yang, M.-T.F. Rodrigues, K. Kalaga, P. Dong, P. Xiao, Y. Zhang, R. Vajtai, P.M. Ajayan, 3D Nanostructured Molybdenum Diselenide/Graphene Foam as Anodes for Long-Cycle Life Lithium-ion Batteries, Electrochim. Acta., 176 (2015) 103-111.

[61] L. Ma, X. Zhou, L. Xu, X. Xu, L. Zhang, W. Chen, Ultrathin few-layered molybdenum selenide/graphene hybrid with superior electrochemical Li-storage performance, J. Power Sources., 285 (2015) 274-280.

[62] H. Wang, X. Wang, L. Wang, J. Wang, D. Jiang, G. Li, Y. Zhang, H. Zhong, Y. Jiang, Phase Transition Mechanism and Electrochemical Properties of Nanocrystalline $\mathrm{MoSe}_{2}$ as Anode Materials for the High Performance Lithium-Ion Battery, J. Phys. Chem. C, 119 (2015) 10197-10205.

[63] X. Yang, Z. Zhang, Y. Fu, Q. Li, Porous hollow carbon spheres decorated with molybdenum diselenide nanosheets as anodes for highly reversible lithium and sodium storage, Nanoscale, 7 (2015) 10198-10203.

[64] Y. Yang, S. Wang, J. Zhang, H. Li, Z. Tang, X. Wang, Nanosheet-assembled $\mathrm{MoSe}_{2}$ and S-doped $\mathrm{MoSe}_{2-\mathrm{x}}$ nanostructures for superior lithium storage properties and hydrogen evolution reactions, Inorg. Chem. Front., 2 (2015) 931-937. 
[65] Y. Liu, M. Zhu, D. Chen, Sheet-like $\mathrm{MoSe}_{2} / \mathrm{C}$ composites with enhanced Li-ion storage properties, J. Mater. Chem. A, 3 (2015) 11857-11862.

[66] Y.N. Ko, S.H. Choi, S.B. Park, Y.C. Kang, Hierarchical MoSe 2 yolk-shell microspheres with superior Na-ion storage properties, Nanoscale, 6 (2014) 10511-10515.

[67] Y. Shi, C. Hua, B. Li, X. Fang, C. Yao, Y. Zhang, Y.-S. Hu, Z. Wang, L. Chen, D. Zhao, G.D. Stucky, Highly Ordered Mesoporous Crystalline $\mathrm{MoSe}_{2}$ Material with Efficient Visible-Light-Driven Photocatalytic Activity and Enhanced Lithium Storage Performance, Adv. Funct. Mater., 23 (2013) 1832-1838. 


\section{Figures and Captions}

Figure. 1 The schematic diagram (a), FTIR spectra of $\mathrm{MoSe}_{2} / \mathrm{PVP}$ before annealing (b), XRD patterns (c) and Raman spectroscopy (d) of CMS/FMS/PMS, and TG curves for PMS (f).

Figure. 2 XPS spectra of Mo 3d (a), Se 3d (b), C 1s (d), and O 1s (e) core level peak regions of PMS.

Figure. 3 (a) S-type interface model (the shorter axis of ox-graphene is perpendicular to the plane of $\mathrm{MoSe}_{2}$ sheet) and its frontier molecular orbitals (HOMO and LUMO), (b) L-type interface model (the longer axis of ox-graphene is perpendicular to the plane of MoSe2 sheet) and its frontier molecular orbitals (HOMO and LUMO), (c) The simplified interface model of $\mathrm{MoSe}_{2}$ sheet on oxidized-fullerene $\left(\mathrm{C}_{60}-\mathrm{O}-\mathrm{Mo}\right)$ and its frontier molecular orbitals (HOMO and LUMO).

Fig. 4 TEM, high resolution TEM (HRTEM), selected area diffraction pattern (SAED), elemental mapping images of CMS (A), FMS(B), PMS(C).

Fig. 5 The Li-storage capability: Comparison of the cycling performances (a) at 1.0 A $\mathrm{g}^{-1}$ in the potential from 3.0 to $0.01 \mathrm{~V}$, and differential charge vs. voltage curve $(\mathrm{dQ} / \mathrm{dV})$ at $100^{\text {th }}(\mathrm{b})$ for those of CMS/FMS/PMS. The rate capability of PMS at different currents (c, e) and dQ/dV of PMS at various cycles (d), the charge platforms $(\mathrm{f}, \mathrm{g})$ and the histogram (h) of PMS at $2.0 \mathrm{~A} \mathrm{~g}^{-1}$ at different cycles.

Figure. 6 The Na-storage performances: Comparison of the cycling stability at $0.1 \mathrm{~A}$ $\mathrm{g}^{-1}$ (a), rate capability at stepwise current densities (b), large-rate cycling properties at 
1.0 $\mathrm{A} \mathrm{g}^{-1}$ (c) for CMS/FMS/PMS, the high-current cycling stabilities of PMS (d), the platforms of the as-made samples after 100 cycles at $0.1 \mathrm{~A} \mathrm{~g}^{-1}(\mathrm{e})$, the DCPs of PMS at $2^{\text {nd }}, 30^{\text {th }}, 60^{\text {th }}$ and $100^{\text {th }}$ for $2.0 \mathrm{~A} \mathrm{~g}^{-1}$.

Figure. 7 Comparison of the charge platforms from the $2^{\text {nd }}$ to $120^{\text {th }}$ cycle for PMS at 1.0 $\mathrm{A} \mathrm{g}^{-1}$ between 3.0 and $0.01 \mathrm{~V}$ (a), Reversible charge capacities $v$ s. cycles number of PMS electrode separated into the scopes of $0.01-1.8$ and $1.8-1.9 \mathrm{~V}(\mathrm{~b})$, the cyclic voltammetry $(\mathrm{CV})$ curves from $1^{\text {st }}$ to $120^{\text {th }}$ for PMS (c), the ex-situ Raman spectra of the $2^{\text {nd }}, 20^{\text {th }}, 60^{\text {th }}, 100^{\text {th }}$ cycles.

Figure. 8 After 100 charge-discharge cycles at the full charged states, ex-situ TEM, HRTEM, SAED of CMS (A), FMS (B), PMS (C).

Figure. 9. The CV curves of PMS (A1, B1) and FMS (A2, B2) at $0.1 \mathrm{mV} \mathrm{s}^{-1}$, the comparison of CV curves for $3^{\text {rd }}$ cycle as LIBs (A3) and (B3), The $20^{\text {th }}$ and $80^{\text {th }}$ cycles EIS, fitting lines and corresponding equivalent circuit for LIBs (C1), the $10^{\text {th }}$ and $40^{\text {th }}$ cycles EIS, fitting lines and corresponding equivalent circuit for SIBs (C2), the simplified model for the equivalent circuit (C3).

Table. 1 The HOMO-LUMO gaps at different theory levels. Unit is eV.

Table. 2 The electrochemical properties of previous reports about $\mathrm{MoSe}_{2}$ for LIBs/SIBs.

Table. 3 The fitting parameters of PMS. 
Figure. 1

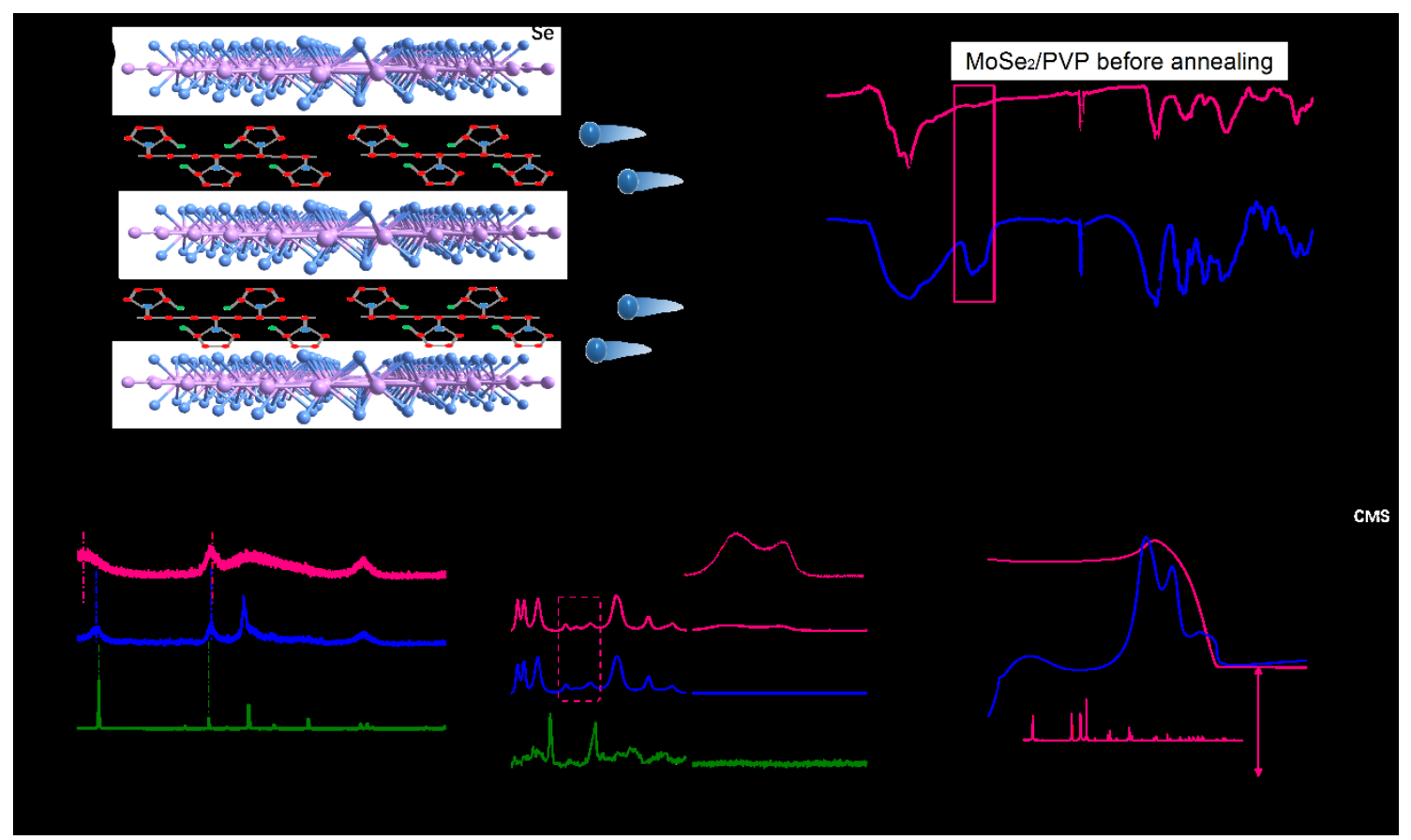


Figure. 2

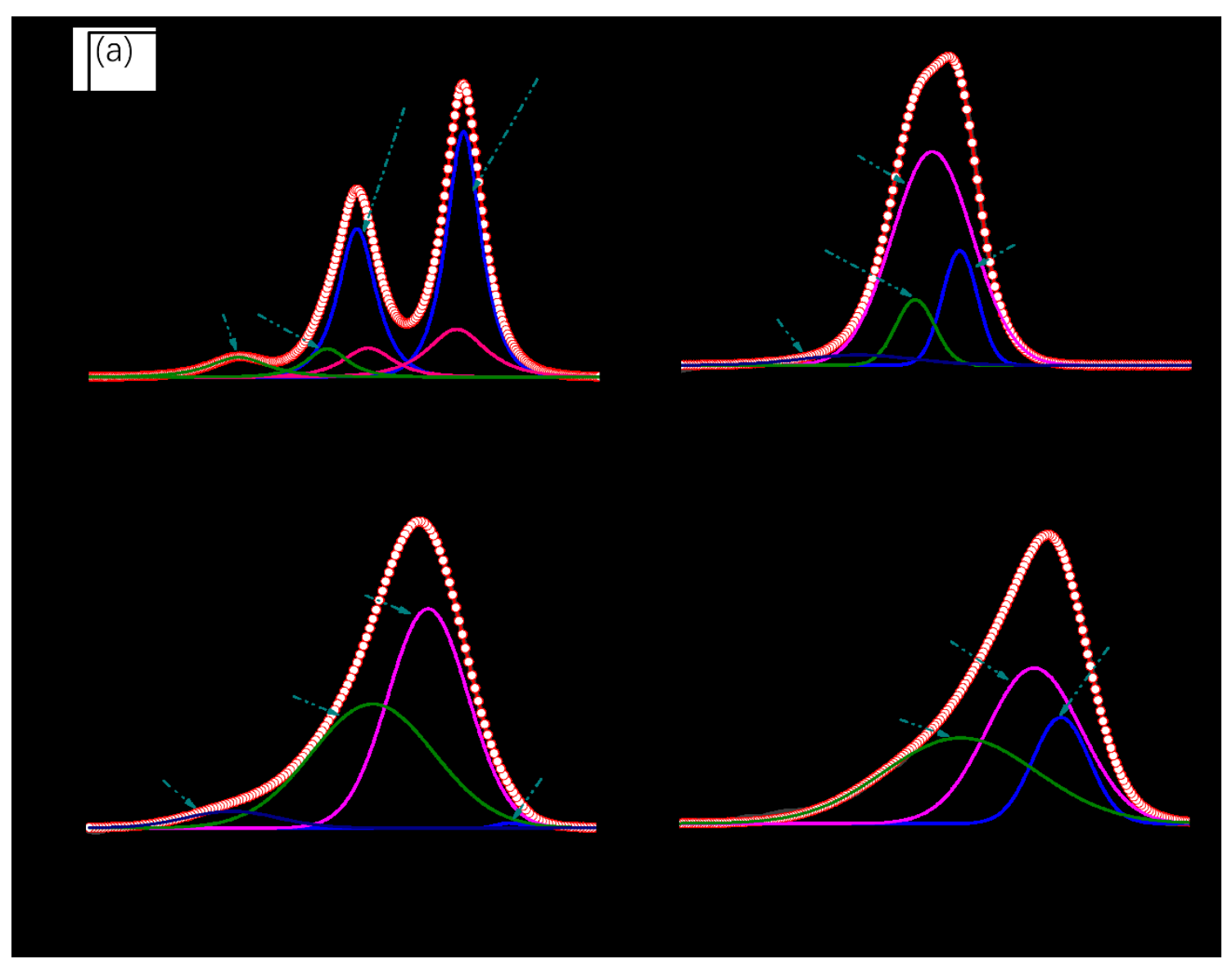


Figure. 3 

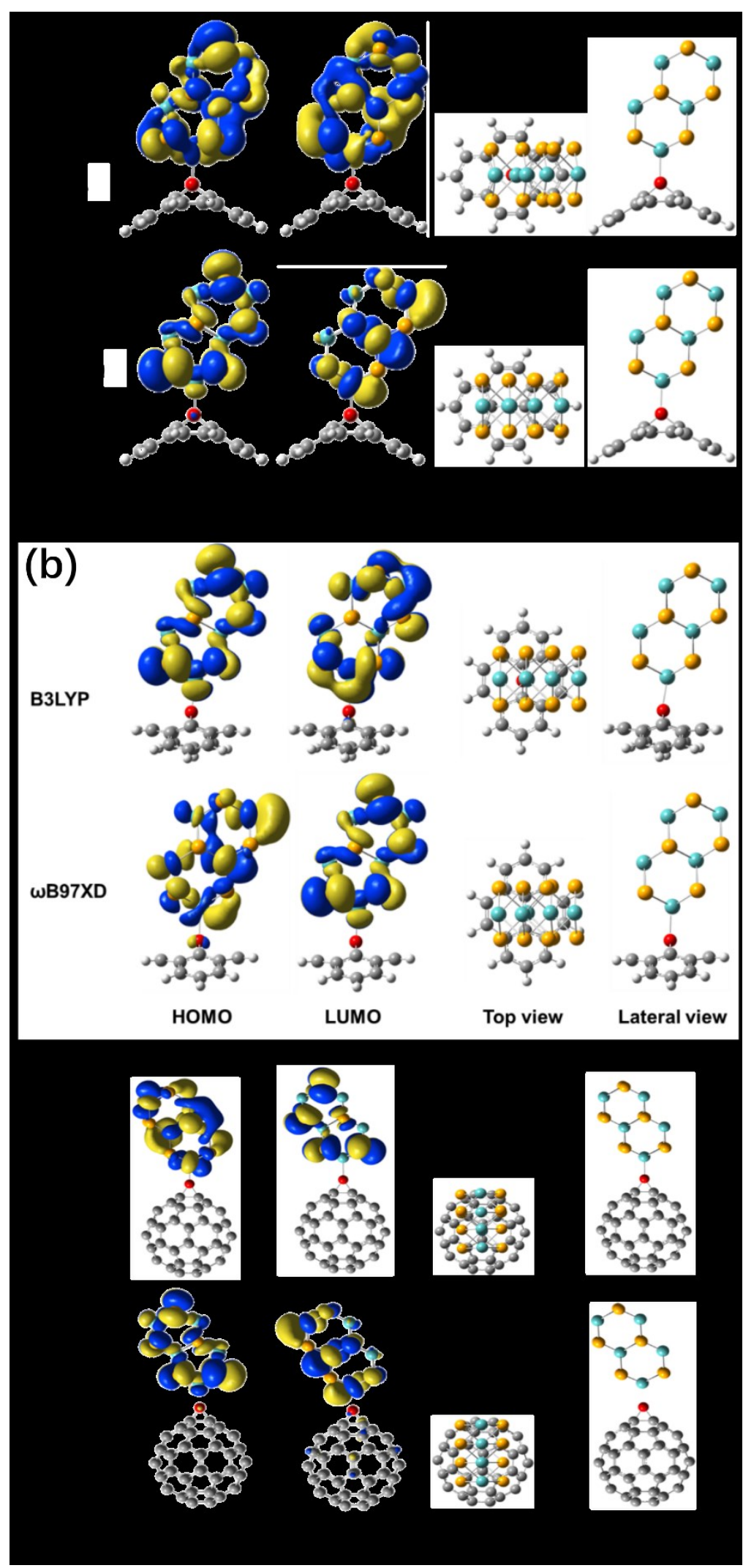
Figure. 4

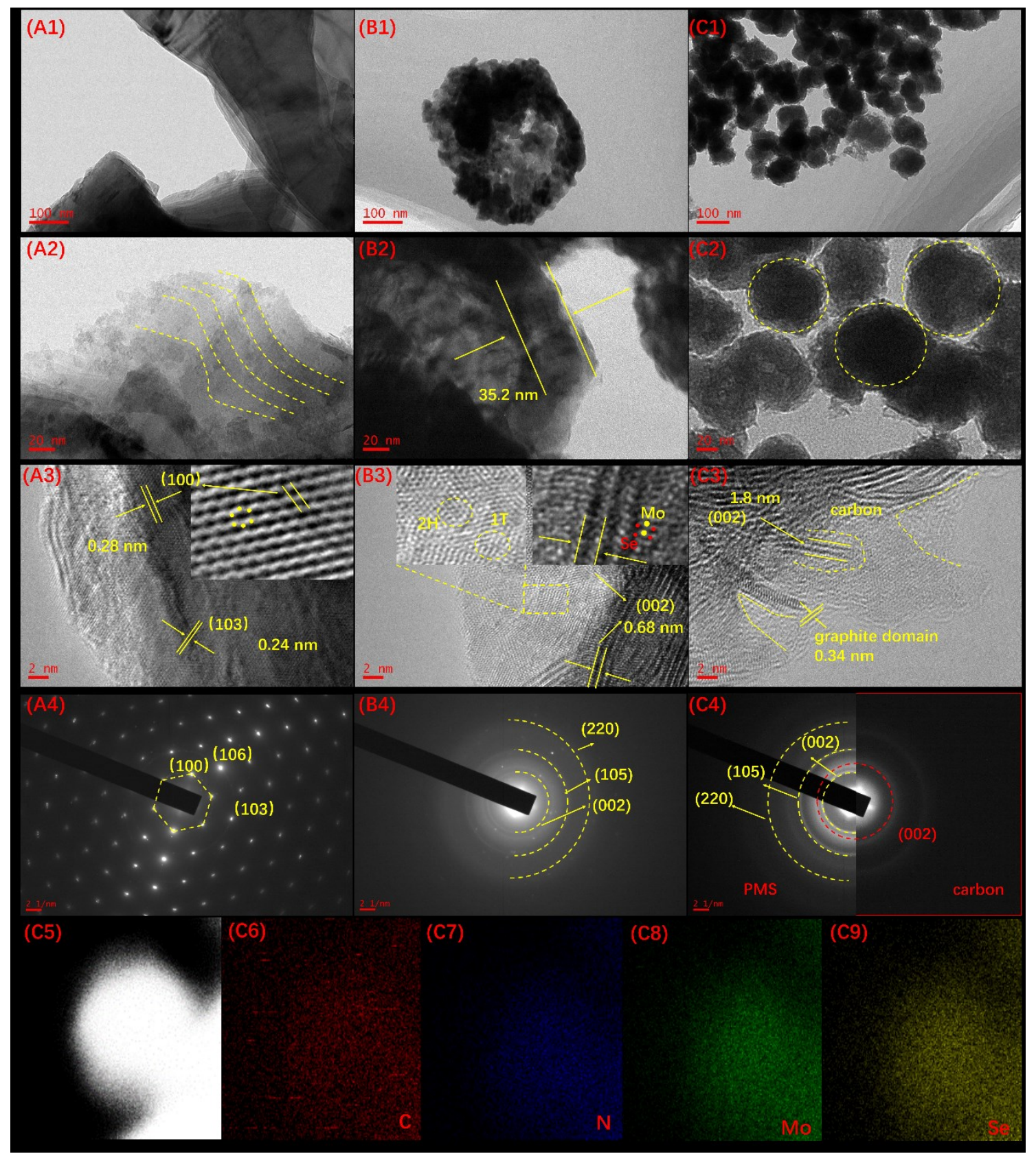


Figure. 5
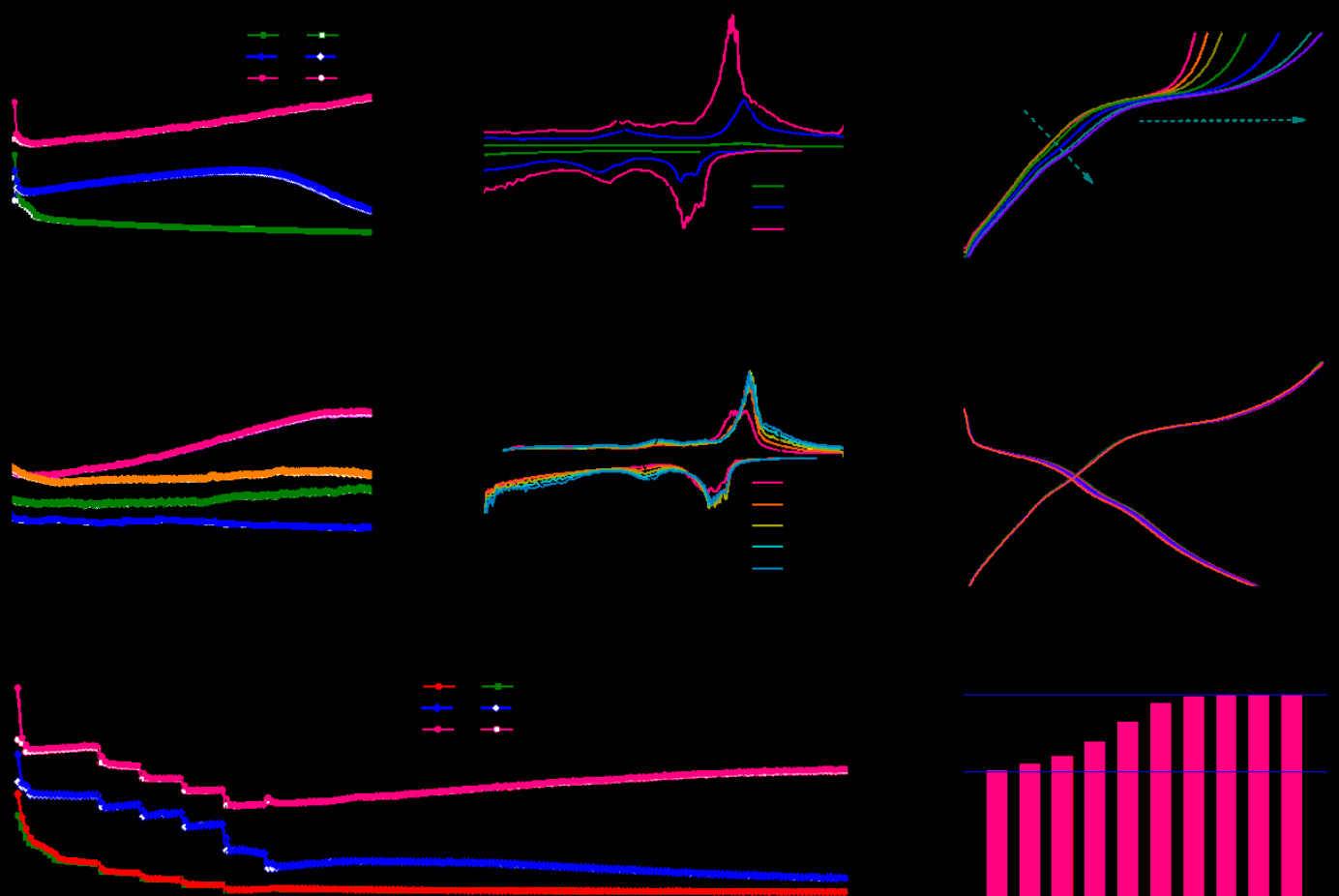
Figure. 6

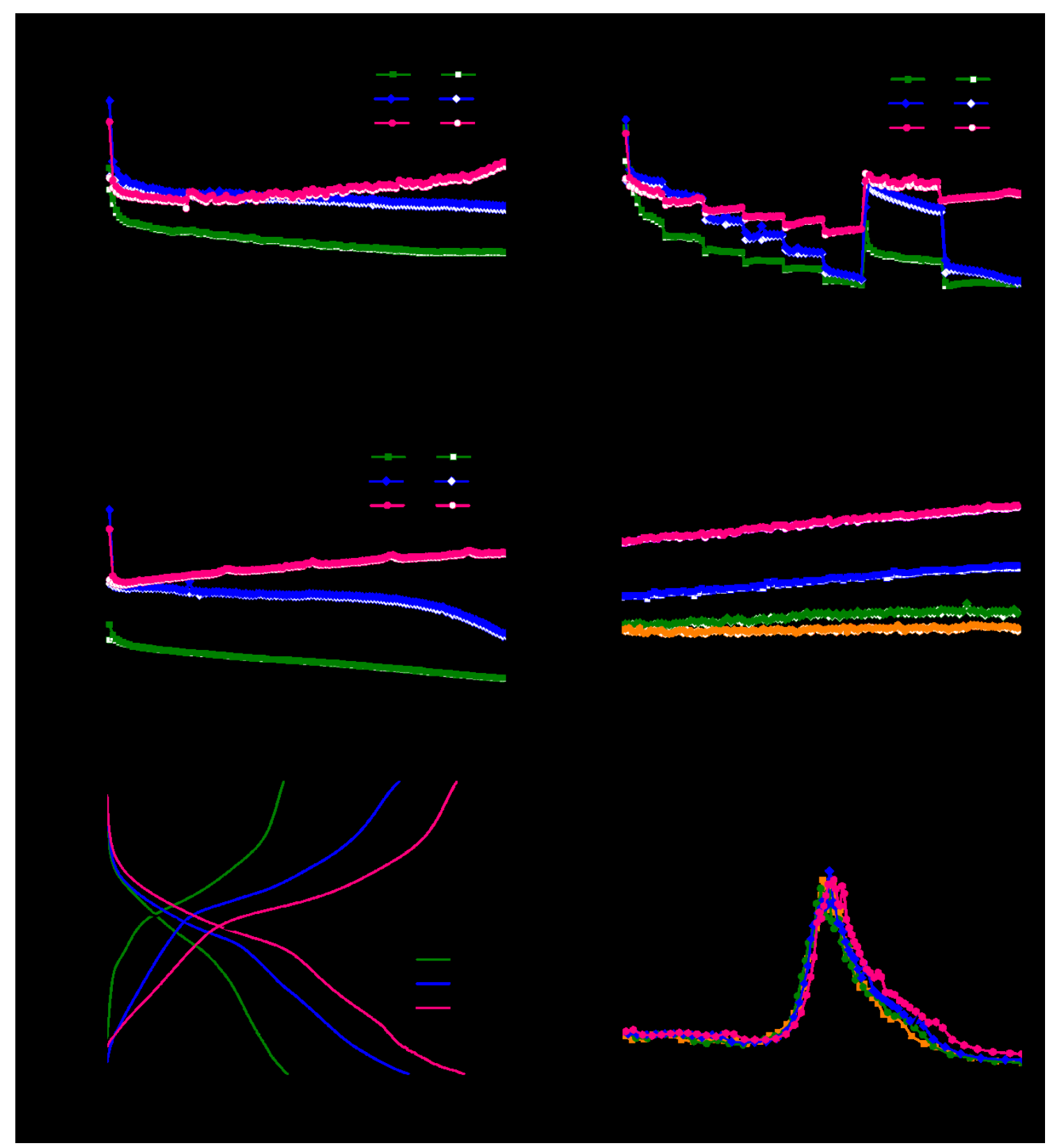


Figure. 7

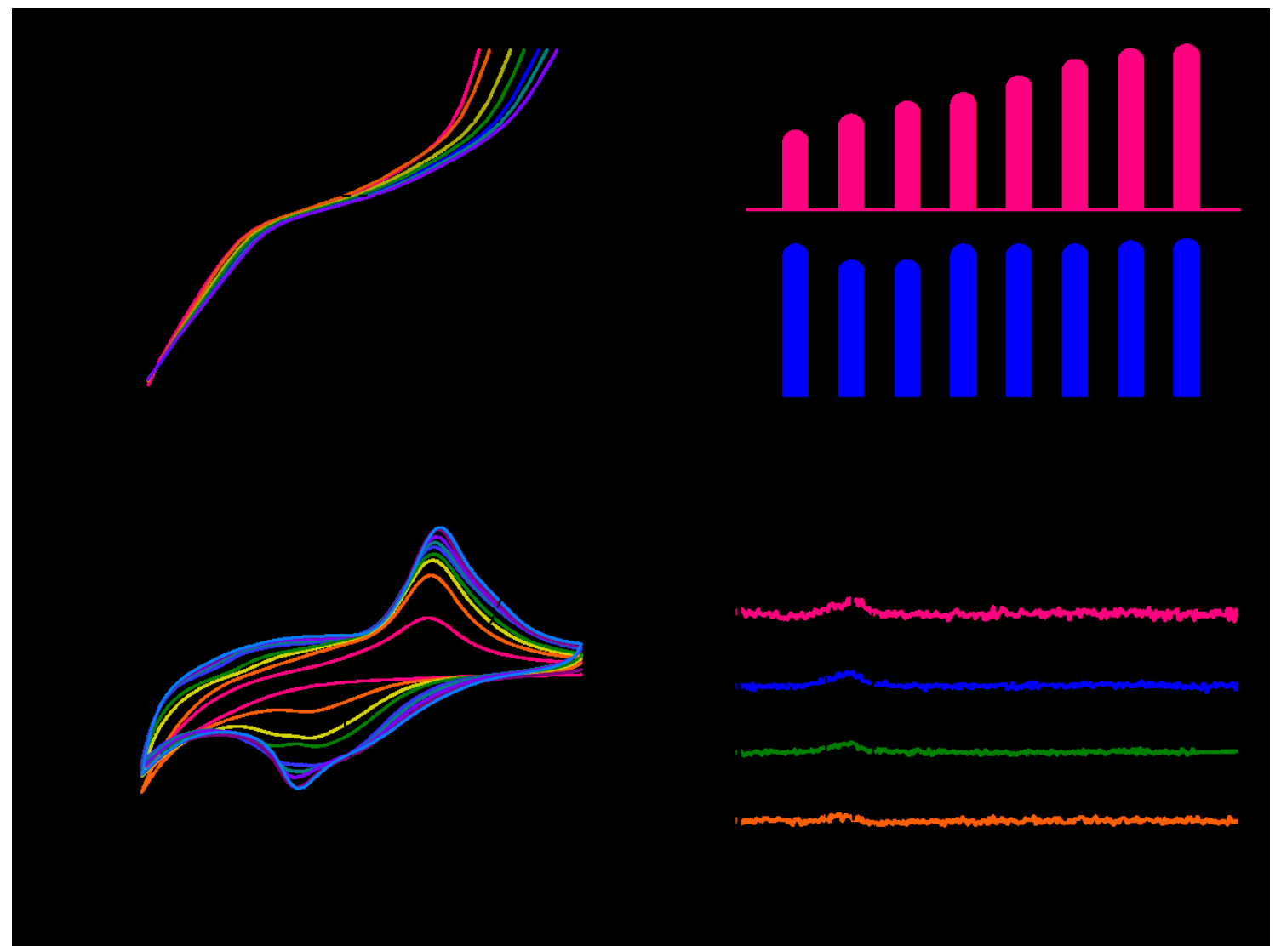


Figure. 8

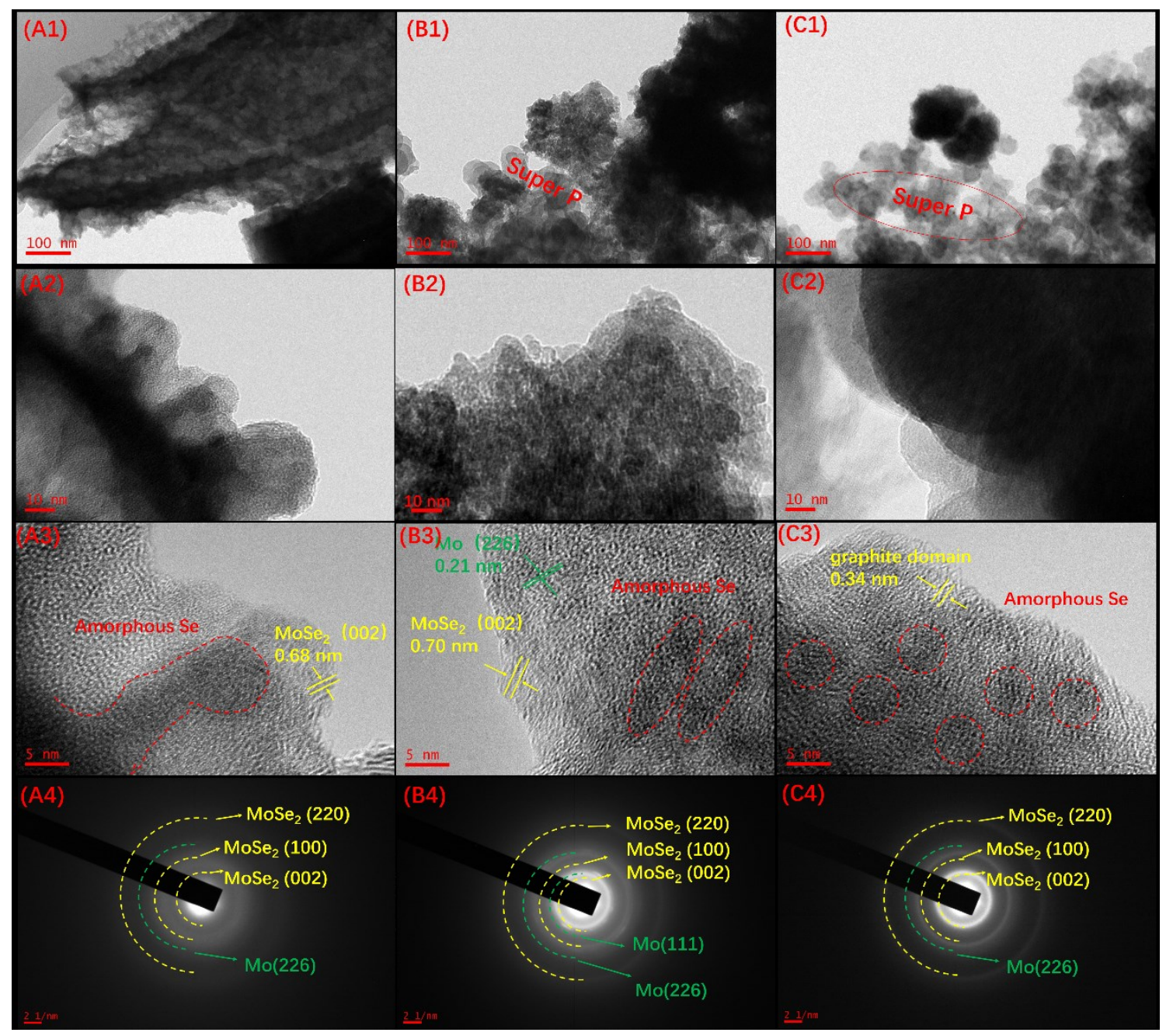


Figure. 9

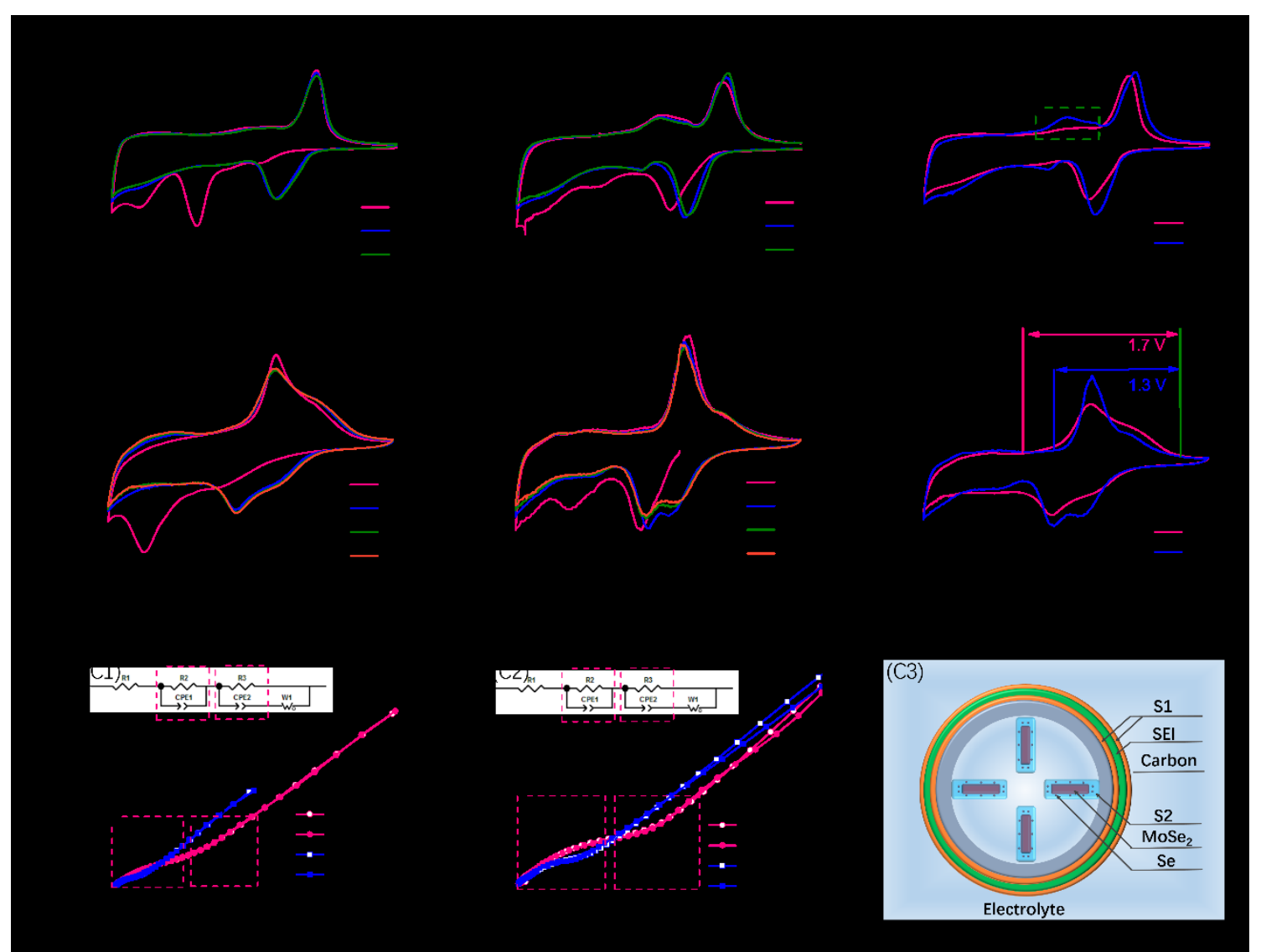


Table 1

\begin{tabular}{|c|c|c|c|c|c|c|}
\hline \multirow{2}{*}{$\begin{array}{l}\text { Simplified } \\
\text { models }\end{array}$} & \multicolumn{2}{|c|}{$\begin{array}{l}\text { B3LYP/6-31G* } \\
\text { /LanL2DZ+ECP }\end{array}$} & \multirow[t]{2}{*}{$\Delta \mathbf{E}_{\text {gap }}$} & \multicolumn{2}{|c|}{$\begin{array}{l}\omega \mathrm{B} 97 \mathrm{XD} / 6-31 \mathrm{G}^{*} \\
/ \mathrm{LanL} 2 \mathrm{DZ}+\mathrm{ECP}\end{array}$} & \multirow{2}{*}{$\Delta \mathbf{E}_{\text {gap }}$} \\
\hline & HOMO & LUMO & & HOMO & LUMO & \\
\hline $\mathrm{MoSe}_{2}$ & -5.17 & -4.63 & 0.55 & -6.88 & -3.07 & 3.81 \\
\hline ox-graphene & -5.61 & -1.41 & 4.20 & -7.46 & -0.27 & 7.17 \\
\hline ox-C60 & -5.93 & -3.32 & 2.62 & -7.76 & -1.96 & 5.79 \\
\hline $\mathbf{S}$ & -4.57 & -3.86 & 0.72 & -6.18 & -2.42 & 3.74 \\
\hline $\mathbf{L}$ & -4.49 & -3.70 & 0.80 & -6.18 & -2.29 & 3.88 \\
\hline C60-O-MoSe2 & -4.60 & -4.05 & 0.54 & -6.26 & -2.53 & 3.74 \\
\hline
\end{tabular}


Table 2

\begin{tabular}{|c|c|c|c|c|}
\hline Materials & Fields & Cycling (mAh g $\left.{ }^{-1}\right)$ & $\begin{array}{l}\text { Rate properties } \\
\qquad\left(\mathrm{mAh} \mathrm{g}^{-1}\right)\end{array}$ & Year/Ref \\
\hline \multirow{4}{*}{$\begin{array}{l}\mathrm{MoSe}_{2} @ \mathrm{~N}-\mathrm{C} \\
\text { nanospheres } \\
(100 \mathrm{~nm})\end{array}$} & $\mathrm{Li}$ & 1219 after 150 cycles at $1.0 \mathrm{~A} \mathrm{g-1}$ & 807 at $2.0 \mathrm{~A} \mathrm{~g} \mathrm{~g}^{-1}$ & \multirow{4}{*}{ This work } \\
\hline & & & 448 at $6.0 \mathrm{~A} \mathrm{~g}^{-1}$ & \\
\hline & $\mathrm{Na}$ & 552 after 120 cycles at $0.1 \mathrm{~A} \mathrm{~g}^{-1}$ & 530 at $1.0 \mathrm{~A} \mathrm{~g}^{-1}$ & \\
\hline & & & 238 at $8.0 \mathrm{~A} \mathrm{~g} \mathrm{~g}^{-1}$ & \\
\hline \multirow[t]{2}{*}{$\mathrm{MoSe}_{2} @$ nanofibers } & $\mathrm{Na}$ & 366.9 after 200 cycles at $0.2 \mathrm{~A} \mathrm{~g}^{-1}$ & 334.2 at $1.5 \mathrm{~A} \mathrm{~g}^{-1}$; & \multirow[t]{2}{*}{$2017[43]$} \\
\hline & & & 320 at $2.0 \mathrm{~A} \mathrm{~g}^{-1}$ & \\
\hline CNTs@C@MoSe2@ & $\mathrm{Li}$ & 1010 after 100 cycles at $0.1 \mathrm{Ag} \mathrm{g}^{-1}$ & 508 at $5 \mathrm{Ag} \mathrm{g}^{-1}$ & $2017[44]$ \\
\hline \multicolumn{5}{|l|}{$\mathrm{Se}$} \\
\hline \multirow[t]{2}{*}{$\mathrm{MoSe}_{2} @ \mathrm{~N}-\mathrm{C}$} & $\mathrm{Li}$ & 906 after 100 cycles at $0.1 \mathrm{Ag}^{-1}$ & 696 at $0.5 \mathrm{~A} \mathrm{~g}^{-1}$ & \multirow[t]{2}{*}{$2017[4]$} \\
\hline & & & 560 at $1.0 \mathrm{~A} \mathrm{~g}^{-1}$ & \\
\hline \multirow{2}{*}{$\begin{array}{l}\text { MoSe2@N-C spheres } \\
0.8 \text { um }\end{array}$} & $\mathrm{Na}$ & 368 after 500 cycles at $0.5 \mathrm{~A} \mathrm{~g}^{-1}$ & 248 at $2.0 \mathrm{~A} \mathrm{~g}^{-1}$ & \multirow[t]{2}{*}{$2017[45]$} \\
\hline & & & 180 at $5.0 \mathrm{~A} \mathrm{~g}^{-1}$ & \\
\hline $\mathrm{MoSe}_{2} @ \mathrm{~N}-\mathrm{C}$ & $\mathrm{Li}$ & 698 after 100 cycles at $0.1 \mathrm{~A} \mathrm{~g}^{-1}$ & 471 at $2.0 \mathrm{~A} \mathrm{~g}^{-1}$ & $2017[3]$ \\
\hline \multicolumn{5}{|l|}{ Microspheres } \\
\hline \multirow[t]{2}{*}{$\mathrm{MoSe}_{2} @ \mathrm{CMK}-5$} & $\mathrm{Li}$ & 788 after 100 cycles at $0.1 \mathrm{~A} \mathrm{~g}^{-1}$ & 609 at $1.0 \mathrm{~A} \mathrm{~g}^{-1}$ & \multirow[t]{2}{*}{$2017[46]$} \\
\hline & & & 542 at $2.0 \mathrm{~A} \mathrm{~g}^{-1}$ & \\
\hline \multirow{2}{*}{$\begin{array}{l}\text { MoSe2@CNT@Grap } \\
\text { hene }\end{array}$} & $\mathrm{Na}$ & 393 after 200 cycles at $1.0 \mathrm{~A} \mathrm{~g}^{-1}$ & 314 at $2.0 \mathrm{~A} \mathrm{~g}^{-1}$ & \multirow[t]{2}{*}{$2017[47]$} \\
\hline & & & 275 at $5.0 \mathrm{~A} \mathrm{~g}^{-1}$ & \\
\hline \multirow[t]{2}{*}{ Flower-like $\mathrm{MoSe}_{2} / \mathrm{C}$} & $\mathrm{Na}$ & 360 after 350 cycles at $0.5 \mathrm{~A} \mathrm{~g}^{-1}$ & 301 at $2.0 \mathrm{~A} \mathrm{~g}^{-1}$ & \multirow[t]{2}{*}{$2017[32]$} \\
\hline & & & 266 at $4.0 \mathrm{~A} \mathrm{~g}^{-1}$ & \\
\hline \multirow{2}{*}{$\begin{array}{l}\mathrm{MoSe}_{2} @ \text { N,P - C } \\
\text { Nanosheets }\end{array}$} & $\mathrm{Na}$ & 378 after 1000 cycles at $0.5 \mathrm{~A} \mathrm{~g}^{-1}$ & 351 at $1.0 \mathrm{~A} \mathrm{~g}^{-1}$ & \multirow[t]{2}{*}{$2017[8]$} \\
\hline & & & 310 at $5.0 \mathrm{~A} \mathrm{~g}^{-1}$ & \\
\hline 1T- $\mathrm{MoSe}_{2} @$ Carbon & $\mathrm{Li}$ & 971 after 100 cycles at $0.3 \mathrm{~A} \mathrm{~g}^{-1}$ & 630 at $3.0 \mathrm{~A} \mathrm{~g}^{-1}$ & $2017[9]$ \\
\hline
\end{tabular}




\begin{tabular}{|c|c|c|c|c|}
\hline $\begin{array}{l}\mathrm{MoSe}_{2} @ \mathrm{~N}-\mathrm{C} \\
\text { Nanosheets }\end{array}$ & $\mathrm{Na}$ & 540 after 100 cycles at $0.1 \mathrm{~A} \mathrm{~g}^{-1}$ & 298 at $2.0 \mathrm{Ag} \mathrm{g}^{-1}$ & $2017[48]$ \\
\hline $\mathrm{MoSe}_{2}$ Nanosheets & $\mathrm{Na}$ & 445 after 100 cycles at $0.1 \mathrm{~A} \mathrm{~g}^{-1}$ & 367 at $5.0 \mathrm{~A} \mathrm{~g}^{-1}$ & 2016[49] \\
\hline coaxial-cable & $\mathrm{Li}$ & 658 after 100 cycles at $0.5 \mathrm{~A} \mathrm{~g}^{-1}$ & 524 at $3.0 \mathrm{~A} \mathrm{~g}^{-1}$ & \multirow{2}{*}{$2016[50]$} \\
\hline $\mathrm{MoSe}_{2} @ \mathrm{C}$ & $\mathrm{Na}$ & 423 after 100 cycles at $0.5 \mathrm{~A} \mathrm{~g}^{-1}$ & 395 at $1.0 \mathrm{~A} \mathrm{~g}^{-1}$ & \\
\hline $\begin{array}{l}\mathrm{MoO} 2 @ \mathrm{MoSe}_{2} \\
\text { heterostructures }\end{array}$ & $\mathrm{Li}$ & $\sim 1000$ after 50 cycles at $0.2 \mathrm{~A} \mathrm{~g}^{-1}$ & 726 at $2.0 \mathrm{~A} \mathrm{~g}^{-1}$ & $2016[51]$ \\
\hline $\begin{array}{l}\mathrm{MoSe}_{2} @ \text { nanoplatelets } \\
@ \text { SWCNTs }\end{array}$ & $\mathrm{Li}$ & 630 after 35 cycles at $0.0315 \mathrm{~A} \mathrm{~g}^{-1}$ & 212 at $0.315 \mathrm{~A} \mathrm{~g}^{-1}$ & $2016[52]$ \\
\hline $\mathrm{MoSe}_{2} / \mathrm{rGO}$ & $\mathrm{Li}$ & 715 after 100 cycles at $0.1 \mathrm{~A} \mathrm{~g}^{-1}$ & $\begin{array}{l}509 \text { at } 1.0 \mathrm{~A} \mathrm{~g}^{-1} \\
436 \text { at } 2.0 \mathrm{~A} \mathrm{~g}^{-1}\end{array}$ & $2016[53]$ \\
\hline $\begin{array}{l}\mathrm{MoSe}_{2} \\
\text { nanosheet@C/TiO2 }\end{array}$ & $\mathrm{Li}$ & 987 after 100 cycles at $0.5 \mathrm{~A} \mathrm{~g}^{-1}$ & 860 at $3.0 \mathrm{~A} \mathrm{~g}^{-1}$ & $2016[54]$ \\
\hline $\mathrm{MoSe}_{2}$ Nanospheres & $\mathrm{Na}$ & 344 after 200 cycle at $0.0422 \mathrm{~A} \mathrm{~g}^{-1}$ & 212 at $4.22 \mathrm{~A} \mathrm{~g}^{-1}$ & $2016[6]$ \\
\hline \multirow{2}{*}{$\begin{array}{l}\text { Fullerene-like } \\
\text { MoSe2@CNT balls }\end{array}$} & $\mathrm{Na}$ & 296 after 250 cycles at $1.0 \mathrm{~A} \mathrm{~g}^{-1}$ & 280 at $3.0 \mathrm{~A} \mathrm{~g}^{-1}$ & \multirow[t]{2}{*}{$2016[55]$} \\
\hline & & & 255 at $5.0 \mathrm{~A} \mathrm{~g}^{-1}$ & \\
\hline \multirow{2}{*}{$\begin{array}{l}\text { MoSe2 Nanosheets@ } \\
\text { rGO }\end{array}$} & $\mathrm{Li}$ & 917 after 100 cycles at $0.5 \mathrm{~A} \mathrm{~g}^{-1}$ & 750 at $1.0 \mathrm{~A} \mathrm{~g}^{-1}$ & \multirow{2}{*}{$2015[56]$} \\
\hline & $\mathrm{Na}$ & 430 after 200 cycles at $0.5 \mathrm{~A} \mathrm{~g}^{-1}$ & 380 at $1.0 \mathrm{~A} \mathrm{~g}^{-1}$ & \\
\hline Mesoporous $\mathrm{MoSe}_{2}$ & $\mathrm{Li}$ & 728 at 30 cycles at $0.0422 \mathrm{Ag}^{-1}$ & $\sim 500$ at $2.0 \mathrm{~A} \mathrm{~g}^{-1}$ & 2015[57] \\
\hline $\mathrm{MoSe}_{2} @$ carbon cloth & $\mathrm{Na}$ & 390 after 100 cycles at $0.2 \mathrm{~A} \mathrm{~g}^{-1}$ & $\begin{array}{l}239 \text { at } 2.0 \mathrm{~A} \mathrm{~g}^{-1} \\
161 \text { at } 5.0 \mathrm{~A} \mathrm{~g}^{-1}\end{array}$ & $2015[58]$ \\
\hline $\mathrm{MoSe}_{2}$ nanoplates & $\mathrm{Na}$ & 369 after 50 cycles at $0.0422 \mathrm{Ag}^{-1}$ & 250 at $4.22 \mathrm{~A} \mathrm{~g}^{-1}$ & 2015[59] \\
\hline 3DMoSe2@Graphene & $\mathrm{Li}$ & 625 after 100 cycles at $0.0422 \mathrm{~A} \mathrm{~g}^{-1}$ & 330 at $0.844 \mathrm{~g}^{-1}$ & $2015[60]$ \\
\hline Few-layered & $\mathrm{Li}$ & 1102 after 100 cycles at $0.1 \mathrm{~A} \mathrm{~g}^{-1}$ & 454 at $1.0 \mathrm{~A} \mathrm{~g}^{-1}$ & $2015[61]$ \\
\hline
\end{tabular}




\begin{tabular}{|c|c|c|c|c|}
\hline $\begin{array}{l}\text { Nanocrystalline } \\
\mathrm{MoSe} \text { ? }\end{array}$ & $\mathrm{Li}$ & 405 after 50 cycles at $0.0422 \mathrm{~A} \mathrm{~g}^{-1}$ & 322 at $4.22 \mathrm{~A} \mathrm{~g}^{-1}$ & $2015[62]$ \\
\hline $\begin{array}{l}\text { hollow carbon } \\
\text { spheres@ } \mathrm{MoSe}_{2}\end{array}$ & $\mathrm{Li}$ & 681 after 100 cycles at $1.0 \mathrm{~A} \mathrm{~g}^{-1}$ & 640 at $3.0 \mathrm{~A} \mathrm{~g}^{-1}$ & $2015[63]$ \\
\hline $\begin{array}{l}\text { hollow carbon } \\
\text { spheres@MoSe } \mathrm{MoS}_{2}\end{array}$ & $\mathrm{Na}$ & 580 after 100 cycles at $0.2 \mathrm{~A} \mathrm{~g}^{-1}$ & 400 at $1.5 \mathrm{~A} \mathrm{~g}^{-1}$ & $2015[63]$ \\
\hline $\begin{array}{l}\text { S-doped } \mathrm{MoSe}_{2-x} \\
\text { nanosheets }\end{array}$ & $\mathrm{Li}$ & 947 after 30 cycles at $0.1 \mathrm{~A} \mathrm{~g}^{-1}$ & 667 at $0.5 \mathrm{~A} \mathrm{~g}^{-1}$ & $2015[64]$ \\
\hline Sheet-like $\mathrm{MoSe}_{2} / \mathrm{C}$ & $\mathrm{Li}$ & 576 at 50 cycles at $0.1 \mathrm{~A} \mathrm{~g}^{-1}$ & 450 at $2.0 \mathrm{~A} \mathrm{~g}^{-1}$ & $2015[65]$ \\
\hline $\begin{array}{l}\text { Hierarchical } \mathrm{MoSe}_{2} \\
\text { yolk-shell } \\
\text { microspheres }\end{array}$ & $\mathrm{Na}$ & 448 after 50 cycles at $0.2 \mathrm{Ag}^{-1}$ & 345 at $1.5 \mathrm{~A} \mathrm{~g}^{-1}$ & $2014[66]$ \\
\hline $\begin{array}{l}\text { Mesoporous } \\
\text { Crystalline } \mathrm{MoSe}_{2}\end{array}$ & $\mathrm{Li}$ & 630 after 35 cycles at $0.25 \mathrm{~A} \mathrm{~g}^{-1}$ & 372 at $0.998 \mathrm{~A} \mathrm{~g}^{-1}$ & $2013[67]$ \\
\hline
\end{tabular}


Table 3

\begin{tabular}{ccccccc}
\hline Samples & CPE1 $(\mathbf{F})$ & $\mathbf{C P E 2}(\mathbf{F})$ & $\mathbf{R}_{\mathbf{2}}(\boldsymbol{\Omega})$ & $\mathbf{R}_{\mathbf{3}}(\boldsymbol{\Omega})$ & $\mathbf{D}\left(\mathbf{c m}^{\mathbf{2}} \mathbf{s}^{-1}\right)$ & $\mathbf{i}\left(\mathbf{m A ~ c m} \mathbf{~ c m}^{-\mathbf{2}}\right)$ \\
\hline PMS-Li-20 $^{\text {th }}$ & $3.8 \times 10^{-4}$ & $6.7 \times 10^{-4}$ & 52 & 89 & $2.26 \times 10^{-16}$ & $3.29 \times 10^{-4}$ \\
PMS-Li-80 $^{\text {th }}$ & $1.7 \times 10^{-4}$ & $6.4 \times 10^{-4}$ & 23 & 39 & $1.75 \times 10^{-15}$ & $7.41 \times 10^{-4}$ \\
PMS-Na-10 $^{\text {th }}$ & $1.6 \times 10^{-4}$ & $9.8 \times 10^{-5}$ & 191 & 275 & $4.83 \times 10^{-17}$ & $8.55 \times 10^{-5}$ \\
PMS-Na-40 $^{\text {th }}$ & $1.1 \times 10^{-4}$ & $1.5 \times 10^{-4}$ & 57 & 172 & $1.56 \times 10^{-16}$ & $3.28 \times 10^{-4}$ \\
\hline
\end{tabular}

